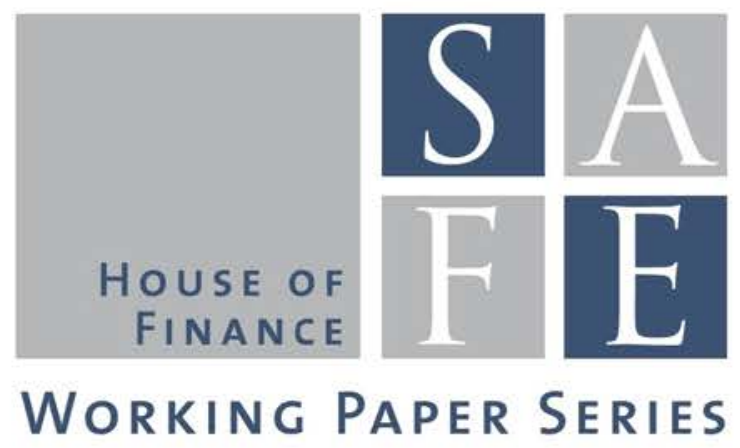

Giulio Girardi - Kathleen W. Hanley - Stanislava Nikolova - Loriana Pelizzon - Mila Getmansky Sherman

\title{
Portfolio Similarity and Asset Liquidation in the Insurance Industry
}

SAFE Working Paper No. 224

SAFE I Sustainable Architecture for Finance in Europe A cooperation of the Center for Financial Studies and Goethe University Frankfurt 


\title{
Portfolio Similarity and Asset Liquidation in the Insurance Industry*
}

\author{
Giulio Girardi $^{\dagger} \quad$ Kathleen W. Hanley ${ }^{\ddagger}$ Stanislava Nikolova ${ }^{\S}$ \\ Loriana Pelizzon Mila Getmansky Sherman"
}

This Draft: July 30, 2018

\begin{abstract}
An important assumption underlying the designation of some insurers as systemically important is that their overlapping portfolio holdings can result in common selling. We measure the overlap in holdings using cosine similarity, and show that insurers with more similar portfolios have larger subsequent common sales. This relationship can be magnified for some insurers when they are regulatory capital constrained or markets are under stress. When faced with an exogenous liquidity shock, insurers with greater portfolio similarity have even larger common sales that impact prices. Our measure can be used by regulators to predict which institutions may contribute most to financial instability through the asset liquidation channel of risk transmission.
\end{abstract}

Keywords: Interconnectedness, Asset Liquidation, Similarity, Financial Stability, Insurance Companies, SIFI

JEL Classification: G11, G18, G2

\footnotetext{
*We thank Sergey Chernenko, Rama Cont, Andrew Ellul, Isil Erel, Mark Flannery, Robin Greenwood, Harald Hau, Pab Jotikasthira, Anastasia Kartasheva, Ralph Koijen, Yijia Lin, Albert J. Menkveld, Alessandro Sbuelz, and participants at the American Finance Association Meeting (AFA 2017), IIF Colloquium on International Insurance Regulatory Issues, London Quantitative Finance Seminar, MIT CSRA Meeting, Temple University Workshop on Systemic Risk and the Insurance Industry, and seminars at Arizona State University, Ohio State University, U.S. Securities and Exchange Commission, and University of Massachusetts-Amherst for helpful comments. We thank Silvia Dalla Fontana, Nicola Mano, Max Riedel, and Matteo Sottocornola for excellent research support. We are grateful to the SAFE Center, funded by the State of Hessen initiative for research, LOEWE, for their financial support. The Securities and Exchange Commission, as a matter of policy, disclaims responsibility for any private publication or statement by any of its employees. The views expressed herein are those of the authors and do not necessarily reflect the views of the Commission or of the authors' colleagues on the staff of the Commission.

${ }^{\dagger}$ Division of Economic and Risk Analysis, U.S. Securities and Exchange Commission, Washington, DC 20549-9040. Email: girardig@sec.gov.

${ }^{\ddagger}$ College of Business and Economics, Lehigh University, Bethlehem, PA 18015. Email: kwh315@lehigh.edu.

${ }^{\S}$ College of Business, University of Nebraska-Lincoln, Lincoln, NE 68588. Email: snikolova2@unl.edu.

`SAFE-Goethe University Frankfurt, Theodor-W.-Adorno Platz 3, 60323 Frankfurt am Main. Email: pelizzon@safe.uni-frankfurt.de.

"Isenberg School of Management, University of Massachusetts, Amherst, MA 01003. Email: msherman@isenberg.umass.edu.
} 
"The severity of the disruption caused by a forced liquidation of Prudential's assets could be amplified by the fact that the investment portfolios of many large insurance companies are composed of similar assets, which could cause significant reductions in asset valuations and losses for those firms. The erosion of capital and potential deleveraging could result in asset fire sales that cause significant damage to the broader economy." (italics added)

Basis for the Financial Stability Oversight Council's Final Determination Regarding Prudential Financial, Inc.

\section{Introduction}

The global financial crisis of 2007-2009 exposed many vulnerabilities within the financial system. It highlighted how interconnectedness among financial entities contributed to the collapse of prominent institutions (e.g., Lehman Brothers, Bear Stearns, Washington Mutual, and Wachovia) and to disruptions in financial markets (e.g., stock, credit default swap, sub-prime mortgage, and money markets). In response, the U.S. Congress passed the Dodd-Frank Wall Street Reform and Consumer Protection Act of 2010. The Act created the Financial Stability Oversight Council (FSOC) and endowed the Council with the authority to implement enhanced prudential standards for bank and nonbank entities designated as Systemically Important Financial Institutions (SIFIs). ${ }^{1}$

In designating certain large insurers as SIFIs, the FSOC expressed a concern that because insurers hold similar portfolios, the need to liquidate similar assets quickly "would cause a fall in asset prices and thereby significantly disrupt trading ... or cause significant losses or funding problems for other firms with similar holdings." ${ }^{2}$ This concern is echoed by Kartasheva (2014) who argues that insurers do not need to fail to propagate risk throughout the financial system; it may be sufficient for them to "fire sell" assets to produce a significant effect. ${ }^{3}$ While there is evidence

\footnotetext{
${ }^{1}$ As noted in the final rule on the Authority to Require Supervision and Regulation of Certain Nonbank Financial Companies, "Section 113 of the Dodd-Frank Wall Street Reform and Consumer Protection Act (Pub. L. 111-203, 124 Stat. 1376 (2010)) authorizes the Financial Stability Oversight Council to determine that a nonbank financial company shall be supervised by the Board of Governors of the Federal Reserve System and shall be subject to prudential standards... if the Council determines that material financial distress of the nonbank financial company, or the nature, scope, size, scale, concentration, interconnectedness, or mix of the activities of the nonbank financial company, could pose a threat to the financial stability of the United States." Similar criteria are used internationally by the Financial Stability Board to designate global systemically important financial institutions (G-SIFIs) (see BIS (2014)).

${ }^{2}$ See Basis for the Financial Stability Oversight Council's Final Determination Regarding Prudential Financial, Inc. available on the FSOC website (FSOC (2013)). The FSOC originally designated four nonbank financial institutions (three of them are insurance companies) as SIFIs: MetLife, Inc.; American International Group, Inc. (AIG); General Electric Capital Corporation, Inc. (GECC); and Prudential Financial, Inc. The Council has since rescinded both AIG's and GECC's SIFI status because of changes the companies made in response to the designation. MetLife's designation was overturned by the courts citing improper economic analysis.

${ }^{3}$ Other risks and activities such as operational risks, reinsurance, non-traditional investments, and financing of insurers have been discussed as affecting financial stability. See Harrington (2009) and Cummins and Weiss (2014) regarding the effect of potential policyholder withdrawals during a financial crisis, Koijen and Yogo (2016) for a
} 
that fire sales by insurers can depress individual sold securities' prices (Ellul et al. (2011), Merrill et al. (2013), and Manconi et al. (2012)), idiosyncratic selling does not necessarily impact financial stability. Instead, selling must be correlated in order to affect large segments of the market or the market as a whole. There is, however, no empirical evidence that insurers' overall portfolio similarity leads to more correlated selling.

In this paper, we address this gap in the literature by investigating whether insurers with more similar portfolios sell more in common. Using cluster analysis, we document that the composition of insurers' holdings is very similar and stable through time. Insurer portfolios can be characterized by three distinct allocation strategies: 1) diversified across corporate bonds, municipal bonds, and government sponsored entity (GSE) fixed-income securities; 2) concentrated in corporate bonds; and 3) concentrated in equity.

Next, we develop a measure of portfolio similarity, between a pair of insurers, based on the cosine similarity of their holdings using 2002-2014 security-level data from the National Association of Insurance Commissioners (NAIC). Cosine similarity is easily interpretable since it is bounded between zero and one. Two insurers with identical portfolios will have a cosine similarity equal to one; and if the portfolios are completely different, the cosine similarity will equal zero. We calculate cosine similarity across asset classes or security issuers held by a pair of insurers. We show that an insurer pair's portfolio similarity is related to pairwise insurer characteristics such as joint size, portfolio concentration, and business line similarity.

We then document that our measure of portfolio similarity can predict the incidence and amount of common sales. We use quarterly buy and sell transactions to construct a measure of common sales as the dot product of an insurer pair's dollar net sales (sales minus purchases) at both the asset class and security issuer level. We show that there is a strong positive relationship between a pair's portfolio similarity and its quarterly common sales during the following year. Consistent with regulatory concerns, we find that Potentially Systemically Important Financial Institutions (PSIFIs), defined as having more than $\$ 50$ billion in total assets, have greater common sales. However, the positive relationship between size and common sales holds true in general, which suggests that the $\$ 50$ billion threshold used by FSOC does not identify the full set of insurers that

discussion of the risks of shadow reinsurance, Geneva Association (2010) and Grace (2010) about the consequences of insurers' increased exposure to derivatives, and Geneva Association (2010) concerning the impact of insurers' increased reliance on short-term funding. 
may contribute to asset liquidation vulnerabilities.

We show that portfolio concentration has a negative relationship with portfolio similarity and common sales, even though some have suggested that it could be a useful metric for identifying SIFIs (Haldane and May (2011), Gai et al. (2011), and Allen et al. (2012)). Our findings support the concerns of Castiglionesi and Navarro (2008), Wagner (2010), Wagner (2011), Ibragimov et al. (2011), and Cont and Wagalath (2016) who suggest that although portfolio diversification reduces each institution's individual probability of failure, it can make the potential for common selling higher.

We provide evidence that public market information, such as return covariance, cannot substitute for portfolio similarity in predicting common selling. A number of recent papers have proposed return covariance as a measure of interconnectedness among financial institutions (Billio et al. (2012), Neale et al. (2012), and Brunetti et al. (2015)). However, we find that the return covariance of a pair of publicly traded insurers has either no relationship or a negative relationship with common sales at both the asset class and issuer levels. Thus, while return covariance may be a useful metric of assessing some aspects of financial institutions' interconnectedness, it does not appear to reflect the type of commonality that can contribute to risk transmission through the asset liquidation channel.

We investigate whether our finding of a positive relationship between portfolio similarity and common sales is due to the liquidity or credit quality of common holdings, since these asset characteristics have been shown to impact insurers' selling decisions when faced with regulatory capital constraints (Ellul et al. (2011) and Ellul et al. (2015)). We decompose portfolio similarity into the similarity of 1) liquid and illiquid asset classes, and 2) downgraded and non-downgraded issuers. ${ }^{4}$ We document that our results are not driven by differences in the liquidity or credit quality of holdings.

We examine whether certain circumstances may magnify the relationship between portfolio similarity and common sales. For example, it may be the case that the relationship is stronger

\footnotetext{
${ }^{4}$ We classify as liquid the following asset classes: equity (all industries), mutual fund shares, US government securities, GSE debt and asset-backed securities, and sovereign bonds. We classify as illiquid the following asset classes: corporate bonds (all industries), municipal bonds (all types), residential mortgage-backed securities, commercial mortgage-backed securities, and all other non-mortgage asset-backed securities. Downgraded (not downgraded) issuers are issuers that are (are not) downgraded from investment grade to non-investment grade in the year after being held.
} 
when both insurers in a pair face regulatory capital constraints or during times of market stress. We first determine the extent to which an insurer is regulatory capital constrained by whether its risk-based capital ratio $(\mathrm{RBC})$ is in the bottom quartile of the sample. Consistent with the prior literature, we find that insurer pairs with low RBC sell more asset classes and issuers in common. Moreover, capital constraints magnify the effect of portfolio similarity on common sales at the asset class, but not at the issuer level. Next, we examine whether the relationship between portfolio similarity and common sales is stronger in times of market stress. We find no evidence of a stronger relationship during the recent financial crisis with one exception: when both insurers in the pair are PSIFIs, higher portfolio similarity leads to even larger common sales at the asset class but not the issuer level. Overall, one could interpret our findings on the magnifying effect of regulatory capital constraints and the financial crisis as evidence that some insurers may have had less leeway in which asset class to dispose of, but not which issuer.

Although the similarity in portfolio holdings predicts common sales, it may not necessarily affect asset prices. To test the relationship between portfolio similarity and price changes, we examine an exogenous shock to the liquidity needs of insurers in the aftermath of Hurricanes Katrina and Rita. During the quarter in which the hurricanes took place, many P\&C insurers with exposure in hurricane-affected states were forced to liquidate holdings to cover policyholder losses. Thus, the advent of the hurricanes provides us with an exogenous shock to insurers' liquidity needs and allows us to study the link between similar holdings and both the magnitude and price impact of forced common sales.

We document that during the quarter of the hurricanes, portfolio similarity increases common sales more for exposed insurer pairs compared to all other pairs. To determine whether this results in a price impact, we examine the change in the value of an exposed pair's joint corporate bond holdings. Specifically, for each pair we construct the weighted average yield spread change of its joint portfolio from the quarter before to the quarter after the hurricanes. We find that exposed pairs with greater portfolio similarity experience a larger increase in the yield spread of their corporate bond holdings compared to non-exposed pairs. We, therefore, conclude that the similarity of insurers' holdings may lead to common sales with the potential to depress asset prices under certain circumstances.

Finally, we propose an insurer-level portfolio similarity measure, computed as the average port- 
folio similarity of an insurer with all other insurers in our sample, to identify specific institutions that might contribute to the asset liquidation channel of risk transmission. We show that this measure can be used to predict the extent to which an individual insurer will sell more in common with all other insurers even after controlling for the insurer's own sales and size. This suggests that the measure can be used in tandem with other risk metrics to identify insurers that may contribute to financial instability.

This paper adds to a growing literature on whether institutional investors' herding in securities and asset liquidation impacts asset prices. Prior studies focus on traded corporate bonds and document that under certain circumstances herding can put downward pressure on prices. For example, Ellul et al. (2011) find that when a bond is held by more regulatory constrained insurers, the effect of a fire sale on bond prices is more pronounced. Nanda et al. (2017) document that the proportion held by insurance companies of a particular bond has explanatory power for yield spreads. Chaderina et al. (2018) show that P\&C insurers tend to sell liquid bonds during times of stress and the more commonly held the bond, the greater the price impact of sales. Chiang and Niehaus (2016) document that life insurers tend to herd when buying and selling corporate bonds, and show that bond returns are abnormally low during the quarter when life insurers exhibit high sell-side herding. Finally, F. Cai et al. (2018) conclude that insurance companies have a greater tendency to herd than mutual funds and pension funds, and institutional sell herding in corporate bonds can be price destabilizing.

In contrast to the above studies, our finding that greater portfolio similarity results in larger common sales, extends to the entirety of insurers' portfolios, instead of being limited to just a particular asset class or periods of market stress. This is an important distinction for several reasons. First, publicly traded corporate bonds comprise only a fifth of the assets held by the insurance industry. ${ }^{5}$ Second, during the financial crisis, the downgrade and subsequent sales of fixed income securities other than corporate bonds (e.g. mortgage-backed securities) contributed to the transmission of risk across these securities' common holders. And finally, insurers may strategically trade across asset classes to mitigate the price impact of sales (Ellul et al. (2015)). For all of these reasons, considering all asset classes in insurers' portfolios when establishing a link

\footnotetext{
${ }^{5}$ According to data from insurers' NAIC filings on Schedule D and from TRACE, in 2014 life and P\&C insurers held $\$ 1.36$ trillion of publicly traded corporate bonds (corporate bonds that trade at least once in 2014). The Federal Reserve's Flow of Funds tables indicate that in 2014 these insurers held $\$ 6.3$ trillion of debt and equity securities.
} 
between portfolio similarity and common sales is important.

In addition, while prior studies examine the impact of insurers' herding on individual corporate bond prices, we document an impact on the value of their corporate bond portfolios. This suggests a feedback effect from investors to asset prices and then back to investors that could be particularly destabilizing. Thus, our portfolio measure can be used by financial stability regulators to identify institutions that may not only affect, but also be affected by, the asset liquidation channel of risk transmission.

Finally, unlike other interconnectedness metrics that rely on equity returns, our measure of portfolio similarity can be used to assess the potential for common selling of any financial institution that discloses holdings even when the institution is not publicly traded. In particular, the measure can be applied to the portfolio holdings of banks (J. Cai et al. (2018)), hedge funds (Sias et al. (2016)), and money market funds, to name a few, allowing regulators to monitor the potential for common sales spillover from a wide variety of market participants.

The remainder of the paper is organized as follows. In Section 2, we describe our sample and variable construction, and present summary statistics. In Section 3, we define our measures of portfolio similarity and common sales. Section 4 investigates the determinants of portfolio similarity and Section 5 presents our analysis of the relationship between portfolio similarity and common sales. The effect of potential magnifiers of this relationship, such as capital constraints, and periods of market stress, is examined in Section 6. Section 7 examines the effect of portfolio similarity on common sales and bond prices when insurers are faced with an exogenous shock to their liquidity needs. We develop an insurer-level measure of portfolio similarity in Section 8, and conclude in Section 9 .

\section{Data}

\subsection{Data Sources and Sample Construction}

We analyze the portfolio similarity and selling behavior of insurers from 2002 to 2014 using information from their statutory filings with the NAIC as distributed by A.M. Best. For each insurer, Parts 1 and 2 of Schedule D of these filings list the par value and book value of every security held at calendar year-end. We retain all non-negative annual holdings. Parts 3,4 and 5 of 
Schedule D list every security an insurer disposed of or purchased during the year along with its par value, disposal/purchase value, and date of disposal/purchase. We exclude any security disposals due to maturity, repayment, calls, or other non-trading activity.

Portfolio holdings, sales, and purchases are reported at the individual security (9-digit CUSIP) level. For each insurer, we aggregate this information to both the issuer level and to the asset class level. We utilize the first 6 digits of each CUSIP as the issuer identifier and aggregate the holdings, sales and purchases of securities with the same 6-digit CUSIP. ${ }^{6}$ When aggregating, we use the par value of fixed-income holdings. Since no comparable number exists for equity securities, we aggregate their book values. We construct quarterly net sales at the issuer level as sales minus purchases, excluding negative values.

In order to aggregate holdings, sales, and purchases to the asset class level, we categorize each security into one of ten primary asset classes: (1) U.S. government securities, (2) GSE debt and asset-backed securities, (3) municipal bonds, (4) sovereign bonds, (5) corporate bonds, (6) RMBS, (7) CMBS, (8) ABS other than RMBS/CMBS, (9) equity (common and preferred stock), and (10) mutual fund shares. We identify RMBS and CMBS using the NAIC-provided list of PIMCO- and BlackRock-modeled securities. ${ }^{7}$ We classify all remaining fixed-income securities using the following sources sequentially: (1) the sector and subsector codes in S\&P RatingXpress, then (2) the type and subtype codes in DataScope, then (3) the issue description and issuer name in NAIC Schedule D, and finally (4) the issuer name and collateral asset type in SDC Platinum's New Issues Module. We further refine corporate bonds, municipal bonds, and equity using the issuer's industry or sector information reported in Schedule D. We categorize corporate bonds and equity as undefined if issuer industry or sector is missing or conflicting. This process yields 34 unique asset classes listed in Appendix A. We then aggregate holdings and net sales (sales minus purchases with negative values excluded) by asset class.

Although Schedule D is filed by each individual insurer, the predominant organizational structure in the insurance industry is the insurance group. Individual companies operate independently

\footnotetext{
${ }^{6}$ The use of the 6-digit CUSIP only approximates the ultimate issuer of the securities as a parent company may have different 6-digit subsidiary CUSIPs.

${ }^{7}$ The NAIC changed its capital assessment methodology for certain asset classes by replacing credit ratings as the measure of expected loss with valuation-based loss estimates from PIMCO for RMBS and BlackRock for CMBS. The NAIC publishes the list of PIMCO- and BlackRock-modeled securities annually. For more information on this regulatory change, see Hanley and Nikolova (2017).
} 
in many ways, but some aspects of their operations are centrally managed, including investment decisions, thus creating strong connections among the members of a group. We, therefore, conduct our analysis at the group level rather than at the individual insurer level. To do so, we aggregate holdings, net sales, and balance sheet information of the initial sample of 5,369 individual insurers to the group level. This aggregation results in a sample of 2,812 different insurance groups. We refer to these as "insurers" throughout the remainder of the paper.

For some of our analysis, we require stock return data, which is only available at the holding company level. Typically, a holding company owns several insurer groups. To aggregate Schedule D and balance sheet data to the holding company level, we match insurer groups to company names in the CRSP/Compustat Merged database and find matches for 107 holding companies. For each holding company, we collect daily holding period returns from the CRSP database.

We also categorize insurers as $\mathrm{P} \& \mathrm{C}$, life, or other (e.g., health, fraternal, and title) if at least half of an insurer's portfolio assets are held in a given year by companies in the group that are in that line of business. Our sample includes 1,746 P\&C and 635 life insurers.

Finally, in order to examine whether systemically important insurers are more likely to have similar portfolios and sell similar assets, we also classify insurers as Potentially Systemically Important Financial Institutions (or PSIFIs) if they have more than $\$ 50$ billion in total assets, excluding assets held in separate accounts, in at least one year of the sample period. Based on this size threshold, we identify 38 insurers as potential candidates for SIFI designation by the FSOC.

\subsection{Portfolio Composition Summary Statistics}

Table 1 presents descriptive statistics for our sample of insurers with detailed variable definitions provided in Appendix B. For each insurer, we compute the time-series average of each variable across the sample period and then report the cross-sectional mean, median, and standard deviation. The average total assets of sample insurers, excluding assets held in separate accounts, are $\$ 2.41$ billion. Life insurers (\$7.54 billion) are much larger than P\&C insurers (\$0.85 billion). ${ }^{8}$ By construction, PSIFIs have significantly more assets ( $\$ 99.8$ billion) compared to non-PSIFIs ( $\$ 0.87$ billion). ${ }^{9}$ The

\footnotetext{
${ }^{8}$ The number of insurers in the "other" category is small, so we do not report summary statistics separately for this type.

${ }^{9}$ The number of PSIFIs and non-PSIFIs does not add up to the total number of insurers, because our PSIFI classification requires data on total assets, which are not available for all insurers in the sample.
} 
average insurer's investment portfolio is $\$ 1.65$ billion. As with total assets, life insurers have larger investment portfolios than P\&C insurers, and PSIFIs have larger investment portfolios than nonPSIFIs.

The table also presents insurers' portfolio composition by asset class. Consistent with the common perception that insurers are important investors in fixed-income markets, we find that fixed-income securities make up $81 \%$ of insurer holdings on average. Corporate bonds (27\%), GSE debt and asset-backed securities (19\%), municipal bonds (14\%), and U.S. government securities $(15 \%)$ represent the largest proportion. Equity holdings are primarily in the form of common and preferred stock, and these securities account for $14 \%$ of the portfolio, on average. Insurers also hold mutual fund shares and these comprise $5 \%$ of average holdings.

Portfolio composition differs by line of business and PSIFI status. Life insurers tend to invest a greater proportion of their portfolio in corporate bonds while $\mathrm{P} \& \mathrm{C}$ insurers hold more municipal bonds and mutual fund shares. PSIFIs invest primarily in corporate bonds (52.7\%), and compared to non-PSIFIs, invest in more illiquid asset classes such as RMBS, CMBS, and ABS. Non-PSIFIs have portfolios that are more balanced among corporate bonds, GSE debt and asset-backed securities, municipal bonds, U.S. government securities, and equity.

Figure 1 summarizes the time-series variation of the insurance industry's aggregate holdings and indicates that only small shifts in and out of asset classes occur through time. Over our sample period, the proportion of insurer portfolios allocated to U.S. government securities increases slightly. The figure also shows that insurers' holdings of RMBS and CMBS increase in the period leading up to the financial crisis and then gradually decrease consistent with the evidence presented in Hanley and Nikolova (2017). Thus, aggregate insurer portfolios are relatively stable.

In examining the composition of insurer holdings, we find that the average insurer in our sample holds 380 different securities issued by 250 issuers. The median number of securities or issuers held is less than half of the sample average, implying that some insurers invest in significantly more securities or issuers than others. Life insurers and PSIFIs invest in more securities and issuers than P\&C insurers and non-PSIFIs. For instance, PSIFIs hold an average of 3,704 different securities issued by 1,888 issuers compared to an average of 223 securities issued by 172 issuers held by non-PSIFIs.

Finally, we measure the level of portfolio concentration at either the asset class $\left(C_{0 n c} A C\right)$ or 
issuer $\left(C_{\text {Conc_I }}\right)$ level using a Herfindahl index, calculated as follows:

$$
\text { Conc }_{i t}=\sum_{k=1}^{K} w_{i t k}^{2}
$$

where $w_{i t k}$ is asset class (issuer) $k$ 's weight in insurer $i$ 's portfolio at the end of year $t$, and is calculated as the dollar value invested in asset class (issuer) $k$ relative to the total dollar value of the insurer's portfolio. The cross-sectional mean, median, and standard deviation of insurers' time-series averages of the two concentration measures are also reported in Table 1. The average asset class concentration in our sample is 0.31 whereas the average issuer concentration is much smaller at 0.16 , which is consistent with the fact that our sample consists of about 32,000 issuers and only 34 asset classes. Life and P\&C insurers have similar portfolio concentrations. PSIFIs' portfolios are less concentrated (more diversified) than those of non-PSIFIs at both the asset class and issuer level, which is not surprising given the large size of the average PSIFI's portfolio.

\subsection{Cluster Analysis of Portfolio Composition}

We next use cluster analysis to examine whether insurers differ in their portfolio allocation strategies and whether their strategies change over time. Cluster analysis allows us to separate insurers into subgroups (clusters) that have closer portfolio connections with each other than with those outside the cluster. We use a standard cluster analysis approach, which we describe in Appendix C. We find that there are three distinct clusters suggesting that insurers employ only a small number of portfolio strategies. This differentiates them from mutual funds, which follow a variety of investment strategies, and provides support for FSOC's assertion that insurers hold similar assets. ${ }^{10}$

The average portfolio composition of the three clusters is displayed in Figure 2. Cluster 1 is relatively diversified across primary asset classes, Cluster 2 is mainly invested in corporate bonds, and Cluster 3 is dominated by equity. In terms of the number of insurers in each cluster, Clusters 1 and 2 are evenly populated with approximately $45 \%$ of sample insurers in each cluster. The remaining $10 \%$ of insurers are in Cluster 3. If we conduct the cluster analysis by year, the optimal

\footnotetext{
${ }^{10}$ For example, common mutual fund types based on investment strategy include equity funds (large-cap, midcap/small-cap, foreign, emerging markets), bond funds (intermediate, short-term, inflation protected, world), balanced funds, target date funds, and real estate funds.
} 
number of clusters remains at three and the composition of each cluster remains similar. ${ }^{11}$

Finally, there is a clear distinction between the portfolio allocation strategies of PSIFIs and those of non-PSIFIs. Figure 3 shows the distribution of PSIFIs and non-PSIFIs in each cluster. PSIFI's portfolios mostly resemble Cluster 2, which is dominated by corporate bonds. Non-PSIFIs' portfolios are similar to Cluster 1, which is diversified across different primary asset classes. These results are consistent with statistics presented in Table 1.

\section{Measures of Portfolio Similarity and Common Sales}

In order to test whether insurers with similar portfolios are likely to trade in a related fashion and subsequently affect asset prices, we need measures that capture the overlap in a pair's portfolios and the overlap in a pair's sales. We construct the pairwise portfolio similarity across all types of securities using cosine similarity either at the asset class or issuer level. Cosine similarity is well-suited to comparing the distance between two vectors and in economics has been used in text analytics (Hanley and Hoberg (2010) and Hanley and Hoberg (2012)) and hedge fund portfolio analysis (Sias et al. (2016)).

We begin by calculating the proportional dollar value of each asset class or issuer of securities held in an insurer's portfolio at calendar year-end. The result is a vector of asset class or issuer portfolio weights. For example, the maximum number of unique issuers in a given year is approximately 32,000 and therefore, each insurer's vector of issuer portfolio weights has a length of 32,000. If an insurer does not invest in a particular issuer in a given year, the portfolio weight for that issuer is set to 0 . We then calculate the cosine similarity between the portfolios of insurers $i$ and $j$ in year $t$ as the dot product of the pair's portfolio weight vectors normalized by the vectors' lengths. That is,

$$
\text { Similarity }_{i j t}=\frac{\boldsymbol{w}_{i t} \cdot \boldsymbol{w}_{j t}}{\left\|\boldsymbol{w}_{i t}\right\|\left\|\boldsymbol{w}_{j t}\right\|}
$$

where $w_{i t}$ is insurer $i$ 's and $w_{j t}$ is insurer $j$ 's vector of weights at year-end $t$. Depending on whether asset class or issuer portfolio weights are used, we refer to this quantity as portfolio similarity at the asset class (Similarity_AC) or issuer (Similarity_I) level.

\footnotetext{
${ }^{11}$ In unreported results, we find that insurers move infrequently between clusters, consistent with the evidence presented in Figure 1.
} 
Because all portfolio weight vectors have elements that are non-negative, this measure of portfolio similarity is bounded in the interval $[0,1]$. Intuitively, the portfolio similarity between two insurers is closer to 1 when their holdings are more similar and equals 0 when they are entirely different.

Table 2 provides summary statistics for our portfolio similarity measures for the whole sample of insurer pairs as well as for PSIFI and non-PSIFI pairs. We define the variable PSIFI_Pair (Non-PSIFI_Pair) equal to 1 if both insurers in a pair are classified as PSIFI (non-PSIFI), and 0 otherwise. The average asset class similarity between a pair of insurers, Similarity_AC, is 0.45 . PSIFI pairs have on average much larger portfolio similarity at the asset class level (0.65) than non-PSIFIs pairs (0.45). The average similarity between a pair of insurers at the issuer level, Similarity_I, is lower (0.12) than at the asset class level, because in our sample there are many more issuers (about 32,000) than asset classes (34). The average issuer-level portfolio similarity is again higher for PSIFI (0.18) than non-PSIFI (0.12) pairs.

Figure 4 depicts the time series of the average pairwise portfolio similarity at the asset class and issuer level for the sample of all insurers and for the subsamples of PSIFI or non-PSIFI pairs. Since non-PSIFI pairs make up the majority of insurers in our sample, their average portfolio similarity closely mimics that of all insurers at both the asset class and issuer level. Non-PSIFIs' average portfolio similarity at the asset class level has declined over the sample period but has remained relatively constant at the issuer level. PSIFI pairs have larger asset class and issuer similarity than non-PSIFI pairs. PSIFI pairs' asset class similarity does not fluctuate much over time, but at the issuer level it has increased. Interestingly, the divergence in portfolio similarity between PSIFIs and non-PSIFIs is larger after the financial crisis.

Prior studies document that insurers consider an asset's liquidity (Ellul et al. (2015)) and credit quality (Ellul et al. (2011)) in their selling decisions when they need to replenish capital and, therefore, these asset characteristics might be important to consider when constructing a measure of portfolio similarity. We disaggregate insurers' holdings into liquid or illiquid asset classes, and downgraded or not downgraded issuers. Liquid asset classes include equity (all industries), mutual fund shares, U.S. government securities, GSE debt and asset-backed securities, and sovereign bonds. Illiquid asset classes include corporate bonds (all industries), municipal bonds (all types), RMBS, CMBS, and ABS. We determine whether or not an issuer is downgraded using credit rating 
information from DataScope. A downgraded issuer is defined as having at least one of its securities downgraded from investment grade to non-investment grade by S\&P, Moody's, or Fitch in the year after an insurer reports holdings it.

Figure 5 shows the proportion of insurer holdings comprised of illiquid asset classes or downgraded issuers. In Panel (a), approximately $70 \%$ of holdings are classified as illiquid, and this proportion is relatively constant through time. Panel (b) shows a significant time trend in the proportion of holdings classified as downgraded. Not surprisingly, holdings of downgraded issuers are largest during the financial crisis when they reach approximately $15 \%$ of insurers' portfolios.

We then decompose the portfolio similarity between a pair of insurers by recomputing the cosine similarity using only liquid (Similarity_AC_Liquid) or illiquid (Similarity_AC_Illiquid) asset classes, and downgraded (Similarity_I_Downgraded) or not downgraded (Similarity_I_NotDowngraded) issuers. Table 2 presents summary statistics for the decomposed similarity measures for all as well as for PSIFI and non-PSIFI pairs. The average portfolio similarity across illiquid and downgraded securities is much larger for PSIFI pairs (0.74 and 0.41, respectively) than for non-PSIFI pairs (0.42 and 0.07 , respectively). To the extent that common holdings of illiquid and downgraded securities are more likely to result in common sales that impact prices, this finding provides support to FSOC's concern over the portfolio composition of large insurers.

To determine which insurers sell similar asset classes or issuers, we construct a measure of common sales. For each insurer, we create a vector of quarterly non-negative net sales (sales minus purchases) of each asset class or security issuer. We then calculate the common selling of insurers $i$ and $j$ as the dot product of the pair of insurers' quarterly net sales vectors. That is,

$$
\text { Common Sales }_{i j t}=\text { Net } \text { Sales }_{i t} \cdot \text { Net } \text { Sales }_{j t}
$$

where Net Salesit is insurer $i$ 's and Net Sales $j$ is insurer $j$ 's vector of non-negative net sales in quarter $t$. Depending on whether asset class or issuer net sales are used, we refer to this quantity as common sales at the asset class (Common Sales_AC) or issuer (Common Sales_I) level. It is important to note that our measure of common sales is based on dollar amounts that are not normalized by total holdings or sales. This allows us to focus on large common sales that are most 
likely to generate a price impact. ${ }^{12}$ Because we are interested in the determinants of common net sales, for each pair in each quarter we only calculate common sales if both insurers have positive net sales.

Figure 6 presents the quarterly time-series average of $L n(1+$ Common Sales $)$ at the asset class and issuer level for the sample of all insurers and for the subsamples of PSIFI and non-PSIFI pairs. The figure shows that most common selling by insurers is done in the last quarter of the year, so in our multivariate analysis we use year-quarter fixed effects to control for this pattern. As with portfolio similarity, PSIFI insurer pairs have greater common sales than non-PSIFIs. Interestingly, we do not see an increase in common selling, whether at the asset class or issuer level, during or around the recent financial crisis.

Table 2 provides additional summary statistics on common sales. In the sample of all insurer pairs the average of $\operatorname{Ln}(1+$ Common Sales_AC $)$ is almost 15 and that of $\operatorname{Ln}(1+$ Common Sales_I $)$ is 6. PSIFI pairs tend to sell more in common both at the asset class (34.42) and issuer (31.89) level compared to non-PSIFI pairs (14.27, and 5.38, respectively). This larger magnitude is not surprising, since PSIFIs have larger portfolios and common sales are not normalized.

\section{Determinants of Portfolio Similarity}

To gain a better understanding of the determinants of pairwise portfolio similarity, we examine its correlation with different insurer characteristics. Because our dependent variable is a pairwise variable, we construct our independent variables in a similar fashion. To capture a pair's businessline similarity, we use indicator variables that equal 1 if both insurers in a pair are life insurers (Life_Pair) or P\&C insurers (PC_Pair), and 0 otherwise. For each pair of insurers, we consider their joint size by using the natural logarithm of the dot product of their holdings' dollar value (Prod_Size). We also measure the insurer pair's joint portfolio concentration as the dot product of their portfolio concentrations at either the asset class (Prod_Conc_AC) or issuer (Prod_Conc_I) level.

Table 3 presents the results from estimating OLS regressions, in which the dependent variable

\footnotetext{
${ }^{12}$ Our results are robust to using the cosine similarity of quarterly net sales instead of the dollar amount of common sales. Cosine similarity of quarterly net sales is calculated analogously to portfolio similarity and is measured as the dot product of a pair's sale weight vectors normalized by the vectors' lengths. The limitation of this method is that it cannot capture the joint magnitude of selling, which may be of interest to regulators.
} 
is pairwise portfolio similarity at the asset class level in columns (1)-(3), or issuer level in columns (4)-(6). In columns (1)-(3), we find that Similarity_ $A C$ between two insurers is greater if they are both life or both P\&C insurers, regardless of whether we examine all, PSIFI or non-PSIFI pairs. This finding is intuitive because insurers likely make asset allocation decisions with their liabilities in mind. Since insurers in the same line of business have similar liabilities, we would expect them to have similar assets as well.

Analyzing portfolio similarity at the issuer level in column (4), we find somewhat different results from those at the asset class level. For the sample of all insurers, a P\&C pair has more similar holdings but a life pair does not. When we examine PSIFI and non-PSIFI pairs separately in columns (5)-(6), we find that this result is limited to non-PSIFI life pairs. PSIFI pairs have greater portfolio similarity when they are both in the same line of business, whether life or P\&C.

Regardless of whether we measure portfolio similarity at the asset class or issuer level, it is always greater if both insurers have the same PSIFI classification. Specifically, when insurers in a pair are either both PSIFI or both non-PSIFI, they have larger portfolio similarity compared to pairs where one insurer is a PSIFI and another is not. Moreover, among non-PSIFI insurers, larger insurer pairs have more similar portfolios as indicated by the positive coefficient on Prod_Size. ${ }^{13}$ One interpretation of the relationship between insurer size and portfolio similarity, is that larger insurers may invest in similar assets because of the scarcity of unique investments at a particular size threshold.

We do not find consistent results with respect to the relationship between a pair's portfolio similarity and portfolio concentration. When measured at the asset class level, concentration tends to be negatively related to portfolio similarity. At the issuer level, this relationship reverses for insurers other than PSIFIs. Non-PSIFI pairs tend to have greater portfolio similarity if they are more concentrated at the issuer class level (columns (4) and (5) in Table 3). This may be due to the propensity of small insurers to invest in well-known issuers, and to draw from the same pool of advisors for their portfolio construction.

\footnotetext{
${ }^{13}$ This finding is similar if instead of the continuous variable Prod_Size we instead use indicator variables for size similarity. These indicator variables equal 1 if we characterize non-PSIFI pairs as either large or small based on whether both insurers in a pair have total assets above or below the median for the sample.
} 


\section{$5 \quad$ Portfolio Similarity and Common Sales}

\subsection{Baseline Analysis}

The FSOC argues that insurers with more similar holdings are likely to have more similar sales, thus exacerbating the price impact of each individual sale and potentially disrupting markets. Common selling can occur if insurers, which are invested in similar assets, sell a pro rata share of their portfolio or if certain characteristics of the assets make them more likely to be sold (e.g., liquidity or credit quality). However, a positive relationship between portfolio similarity and subsequent common sales is not a foregone conclusion. Recognizing the potential for disruption in financial markets and losses to their portfolios due to price impact, insurers may approach asset liquidation decisions strategically to minimize the likelihood of common selling and avoid downward pressure on prices. If this is the case, portfolio similarity may not be related to common sales.

To ascertain whether there is a link between similar holdings and similar sales, we use portfolio similarity to explain both (i) the probability and (ii) magnitude of common sales. For the former, we estimate a probit model in which the dependent variable is an indicator variable that equals 1 if Common Sales $>0$, and 0 otherwise. For the latter, we estimate a tobit model because, as

shown in Table 2, the dependent variable Common Sales equals 0 for many insurer pairs other than PSIFIs.

The estimation results are presented in Table 4 and indicate a strong positive relationship between portfolio similarity, and the probability and magnitude of common sales. The coefficients on Similarity_AC and Similarity_I are positive and significant in columns (1)-(6). That is, pairs of insurers that have more similar holdings are more likely to sell similar asset classes and issuers. The relationship is present even after controlling for other pair characteristics that may affect common selling, and in both PSIFI and non-PSIFI subsamples.

We also document that common sales are related to a pair's business line similarity, joint size, and joint portfolio concentration, holding portfolio similarity constant. For example, if both insurers in a pair are $\mathrm{P} \& \mathrm{C}$ insurers, the pair has greater common sales at both the asset class and issuer levels. The effect of business line similarity reverses for life pairs, which have lower common sales. The different results for $\mathrm{P} \& \mathrm{C}$ and life pairs may be due to life and $\mathrm{P} \& \mathrm{C}$ insurers having different investment horizons. Life insurers are more likely to be long-term investors while $\mathrm{P} \& \mathrm{C}$ insurers are 
more likely to experience stochastic shocks to liabilities that necessitate asset liquidation.

We find that insurer size is related to common sales. For example, pairs of PSIFI insurers have greater common sales than other insurers. Although non-PSIFIs have lower common sales than PSIFIs, among them, larger pairs have larger common sales as shown in columns (4) and (8). Thus, our findings support FSOC's use of firm size as one criteria for non-bank SIFI designation, but also suggest that the $\$ 50$ billion size threshold does not appear to be particularly meaningful.

We also document that the joint portfolio concentration of a pair, either at the asset class or issuer level, leads to a decrease in both the probability and magnitude of common sales. The negative coefficient on Prod_Conc indicates that the more diversified a pair's holdings, the more likely and the greater its common sales. This finding is consistent with a number of papers, which have suggested that portfolio diversification increases the potential for common selling that may lead to financial instability (Haldane and May (2011), Gai et al. (2011), and Allen et al. (2012)).

The results presented in this section confirm FSOC's concern that portfolio similarity is an important determinant of common sales. Thus, our measure could be used to monitor insurers and identify those insurers that may contribute more to the asset liquidation channel of systemic risk transmission.

\subsection{Return Covariance and Common Sales}

We next examine whether a pair's stock return covariance contains the same information about common sales as our measure of portfolio similarity. Prior studies have proposed the use of marketbased measures to quantify the interconnectedness of financial institutions. Specifically, Billio et al. (2012), Neale et al. (2012), and Brunetti et al. (2015) argue that return covariance captures, at the aggregate level, the on- and off-balance-sheet links between and within the insurance and banking industries. However, this and other market-based measures of interconnectedness cannot be constructed for many financial institutions that are not publicly-traded (e.g. hedge funds, and private banks and insurers) but may contribute to the asset liquidation channel of risk transmission. Since some of these institutions report portfolio holdings, our similarity measure may be a useful metric for forecasting these institutions' potential for common selling.

In order to determine whether a pair's covariance of stock returns (RetCov_Pair) is a good proxy for portfolio similarity when it comes to predicting common sales, we first use it instead of 
portfolio similarity in our base specification. The estimation results at the asset class and issuer level in columns (1) and (5) of Table 5, respectively, indicate no evidence of a relationship between RetCov_Pair and common sales. When a pair's portfolio similarity is included in the remaining specifications alongside return covariance, the relationship between portfolio similarity and common sales remains positive and significant, while that between return covariance and common sales is either negative or insignificant. Thus, we conclude that an insurer pair's return covariance is not a substitute for portfolio similarity when it comes to predicting the pair's common selling. This is likely due to the fact that return covariance reflects many different aspects of a pair's interconnectedness in addition to similarity in portfolio allocation.

\subsection{Effect of Asset Liquidity and Issuer Downgrades}

Since prior studies document that individual insurers sell liquid (Ellul et al. (2015)) and downgraded (Ellul et al. (2011)) assets when they need to replenish regulatory capital, we explore whether the relationship between portfolio similarity and common sales is due to insurers' common holdings of these types of assets. Specifically, we decompose the portfolio similarity between a pair of insurers by recomputing the cosine similarity using only liquid (Similarity_AC_Liquid) or illiquid (Similarity_AC_Illiquid) asset classes, and downgraded (Similarity_I_Downgraded) or not downgraded (Similarity_I_NotDowngraded) issuers. Cont and Schaanning (2018) propose a measure that captures liquidity-weighted overlap between banks' portfolios, and show they are related to fire sale losses. We then regress common sales on the decomposed portfolio similarity measures.

Table 6 presents the estimation results, and indicates that the positive relationship between portfolio similarity and common sales is not driven by the liquidity or credit quality of insurers' common holdings. In all specifications, the coefficient on each of the decomposed portfolio similarities - liquid, illiquid, downgraded, and not downgraded - is highly significant and positive. Thus, common sales are larger regardless of whether insurers hold more similar liquid or illiquid asset classes, and more similar downgraded or not downgraded issuers. 


\section{Magnifiers of Portfolio Similarity's Effect on Common Sales}

In this section, we examine whether certain factors can contribute to financial instability by magnifying the relationship between portfolio similarity and common sales. Because we are interested in magnification, we focus on the subsample of pairs that sell at least one asset class or issuer in common (i.e., Common Sales $>0$ ). By doing so, we no longer need a tobit specification and can run OLS regressions to investigate whether capital constraints and periods of market stress can act as magnifiers.

\subsection{Regulatory Capital Constraints}

The literature has documented that firms subject to capital requirements liquidate assets quickly when their regulatory capital is depleted. These regulation-induced fire sales can have a disruptive effect on markets by putting downward pressure on prices (Ellul et al. (2011) and Merrill et al. (2013)). The effect of fire sales may be magnified to the extent that insurers with low regulatory capital and similar holdings liquidate more of these holdings. In this section, we examine whether the relationship between portfolio similarity and common sales is stronger for capital constrained insurers.

We assess the extent to which an insurer is regulatory capital constrained through its ratio of statutory to risk-based capital (RBC ratio). A large $\mathrm{RBC}$ ratio can potentially reduce the need to liquidate assets and can provide a buffer against a shock to an insurer's balance sheet. To allow for non-linearity in the relationship between RBC and common sales, we consider both the level of RBC and whether RBC is relatively low. Thus, our set of independent variables includes both the natural logarithm of the product of RBC for an insurer pair (Prod_RBC), and a pairwise indicator variable ( $R B C_{-} L_{o} w_{-}$Pair) equal to 1 if both insurers' $\mathrm{RBC}$ ratios are at or below the bottom quartile of the sample and to 0 otherwise. ${ }^{14}$ If the effect of portfolio similarity on a pair's common selling is more pronounced when both insurers in the pair are capital constrained, then the interaction term Similarity $*$ RBC_Low_Pair should be positively related to common sales.

Table 7 presents our analysis on the magnifying effect of regulatory capital constraints. We confirm the literature's findings that insurers with lower capital are more likely to sell securities in

\footnotetext{
${ }^{14}$ Our results are robust to using the median $\mathrm{RBC}$ as the cutoff.
} 
common. The coefficient of Prod_RBC is significantly negative, and the coefficient of $R B C_{-} L o w_{-} P a i r$ is significantly positive, for the sample as a whole in columns (1) and (4) and for non-PSIFI pairs in columns (3) and (6). Moreover, the effect of capital constraints is magnified when portfolio similarity is taken into consideration as the coefficient on Similarity * RBC_Low_Pair is positive and significant. We find evidence that at the asset class level capital constrained pairs with more similar portfolios have even larger common sales than non-constrained pairs. We do not find a similar magnifying effect at the issuer level. ${ }^{15}$

\subsection{The Financial Crisis}

Since common selling may be of particular concern when markets are under stress, we examine whether the relationship between portfolio similarity and selling is stronger during the recent financial crisis. To do so, we create two indicator variables, Crisis and Post-Crisis, that equal 1 during 2007-2009 and 2010-2014 respectively, and 0 otherwise. We then include these indicator variables along with their interactions with portfolio similarity in our baseline regression.

The estimation results presented in Table 8 indicate that a period of market stress is a magnifier only for PSIFIs and only at the asset class level. The coefficient on Similarity $*$ Crisis is insignificant in all other cases. One interpretation of this finding is that, during the crisis, PSIFIs may have had less flexibility when choosing which asset class to sell, but not which issuer. As Table 1 shows, PSIFIs have larger holdings of illiquid asset classes than non-PSIFIs. Because during the crisis trading some of these asset classes became difficult (e.g., RMBS, CMBS, and ABS), PSIFIs may have resorted to selling liquid asset classes in their portfolios. This is consistent with Figure 3, which shows that from 2007 to 2009 a considerable number of PSIFIs switch from Cluster 3 (mainly equities) to Cluster 2 (mainly fixed-income), and implies potentially pervasive common sales of equities by PSIFIs.

We document several interesting patterns in the relationship between portfolio similarity and common sales in the post-crisis period. At the asset class level, PSIFI pairs with greater portfolio similarity sell more in common after the crisis than before the crisis. The coefficient on Similarity* Post-Crisis is significant in column (2). In contrast, at the issuer level, all insurer pairs with more

\footnotetext{
${ }^{15}$ We do not find evidence that RBC affects the size of the common sales for PSIFI pairs (columns (2) and (5)). This is maybe because large insurers tend to be very well-capitalized and thus, their selling behavior is unlikely to be affected by regulatory capital. (Indeed, $R B C_{-} L$ Low_Pair $=1$ for only 36 PSIFI pair-years out of 23,692 in our sample.)
} 
similar portfolios have lower common sales in the post-crisis than pre-crisis period. This finding may indicate that as a result of their experience during the crisis, post-crisis insurers invested in similar issuers may avoid common selling in an attempt to mitigate its negative price impact.

In conclusion, our findings in this section suggest that PSIFI pairs sell more similar asset classes during the financial crisis. Although this heightened common selling does not appear to take place at the issuer level, there may be a risk of negative spillovers across securities belonging to the same asset class consistent with Khandani and Lo (2011). These findings supports regulators' concern that PSIFIs may engage in common selling during times of market stress.

\section{Hurricanes Katrina and Rita}

In this section, we investigate whether our finding that insurers with more similar portfolios have larger common sales persists in the context of forced sales and whether portfolio similarity can predict the magnitude of the price impact on insurers' portfolios. We do so by examining an exogenous shock to insurers' liquidity needs. The exogenous shock we consider is Hurricanes Katrina and Rita, which made landfall in Florida on August 25, 2005, and Louisiana on September 24, 2005, respectively. According to the National Oceanic and Atmospheric Administration, total damages from the hurricanes were $\$ 160$ billion. The impact on $\mathrm{P} \& \mathrm{C}$ insurers was particularly severe with $\$ 41$ billion of filed claims on personal property, vehicle, and business policies. ${ }^{16}$ Since the large number of claims most likely necessitated the sale of securities to cover losses, we use this natural disaster as a shock to the liquidity needs of $\mathrm{P} \& \mathrm{C}$ insurers with significant exposure in the hurricane-affected states. ${ }^{17}$ This empirical setup allows us to minimize the incidence of regular portfolio rebalancing and of selling motivated by changing issuer fundamentals, to isolate the effect of portfolio similarity on forced common sales and the resultant effect on prices. ${ }^{18}$

\footnotetext{
${ }^{16}$ See the Insurance Information Institute publication "Infographic: Hurricane Katrina 10 Years Later" at https://www.iii.org/article/infographic-hurricane-katrina-10-years-later.

${ }^{17}$ Although 1,833 lives were lost during the storm, many of them were uninsured. Therefore, life insurers were relatively unaffected by the hurricanes and are thus excluded from the analysis. See Towers Watson, "Hurricane Katrina: Analysis of the Impact on the Insurance Industry" at https://biotech.law.lsu.edu/blog/impact-of-hurricanekatrina-on-the-insurance-industry-towers-watson.pdf.

${ }^{18}$ The occurrence of Hurricane Katrina has been used in several recent studies. Manconi et al. (2016) exploit the impact of the hurricane on insurers' corporate bond sales to examine the drop in bondholder concentration. Liu (2016) finds that insurers without hurricane exposure exploit the discounted prices after disasters to realize significant profits. Finally, Chaderina et al. (2018) show that insurers are more likely to fire sell liquid assets when faced with an exogenous liquidity shock.
} 


\subsection{Effect on Common Sales}

We collect data for each $\mathrm{P} \& \mathrm{C}$ insurer on the amount of premiums written in the two states most affected by Hurricanes Katrina and Rita: Louisiana and Mississippi. ${ }^{19}$ We define a pair of insurers as being exposed to potential losses from these hurricanes, Exposed, if both insurers' premiums written in hurricane-affected states relative to total premiums written in each year, are in the top quartile of the sample. We create an indicator variable, Hurricane, equal to 1 in 2005Q3, and 0 otherwise. If portfolio similarity can predict forced selling in common, exposed insurers with more similar portfolios will have larger common sales during the quarter of Hurricanes Katrina and Rita. That is, we hypothesize that the effect of the triple interaction Similarity_I ${ }^{*}$ Hurricane $^{*}$ Exposed on common sales should be positive and significant. ${ }^{20}$

The estimation results are presented in Table 9 and provide evidence consistent with our hypothesis. The coefficient on Similarity_I*Hurricane*Exposed is positive and significant in columns (1) and (2). Column (1) includes all insurer pairs and column (2) excludes mixed pairs, i.e., pairs of an exposed and a non-exposed insurers. When we limit our sample to just exposed insurers in column (3), we find that their portfolio similarity results in larger common sales during the quarter of the hurricanes than during any other quarter.

The results in Table 9 also indicate that during the quarter of the hurricanes exposed insurers sell more in common regardless of portfolio similarity, consistent with Manconi et al. (2016). The coefficient on Hurricane ${ }^{*}$ Exposed in both columns (1) and (2) is positive and significant. In contrast, the negative coefficient on Hurricane in these columns implies that insurers without a significant exposure in hurricane-affected states sell less in common. This could be because non-exposed insurers attempt to avoid common sales at a time when markets are being negatively affected by the selling behavior of exposed insurers. We also document that Similarity_I is positive and significant in all columns, which reiterates our earlier conclusion that greater portfolio similarity always results in larger common sales.

\footnotetext{
${ }^{19}$ Although several states were affected, the majority (93\%) of insured losses occurred in Louisiana and Mississippi.

${ }^{20}$ We limit our analysis to portfolio similarity at the issuer level to be consistent with the next section where we focus on a single primary asset class, corporate bonds.
} 


\subsection{Effect of Portfolio Similarity on Yields}

The prior subsection documents that when faced with a liquidity shock insurers with more similar portfolios sell even more in common. In this subsection, we examine whether this behavior impacts asset prices. Specifically, we investigate whether assets held by insurer pairs with greater portfolio similarity experience a larger drop in value around the time of Hurricanes Katrina and Rita. Our approach is similar to that of Manconi et al. (2012) who examine whether the exposure of institutional investors to securitized bonds before the onset of the financial crisis, increases yield spreads more during the crisis. Since we are interested in measuring the price impact on illiquid assets, and because fixed-income pricing data is only available for corporate bonds, the analysis in this section is limited to corporate bonds.

To match the pairwise nature of our portfolio similarity measure, we similarly construct a pairwise measure of the change in asset prices. Specifically, for each pair of insurers $i$ and $j, \Delta Y S_{i, j}$ is the change in the yield spread of the pair's joint corporate bond portfolio from the quarter prior to Hurricanes Katrina and Rita to the quarter after. To construct this measure, we start with all bonds in the TRACE Enhanced database for which a yield to maturity is available at the end of 2005Q2 and 2005Q4. For each bond, we calculate the yield spread as the difference between the bond's yield to maturity from TRACE Enhanced and the yield to maturity on a maturity-matched Treasury bond from the H.15. Federal Reserve Release. ${ }^{21}$ The yield spread change is a bond's yield spread at the end of 2005Q4 minus the yield spread at the end of 2005Q2. We construct each insurer's portfolio yield spread change as the weighted average yield spread change of the corporate bonds in its portfolio. That is,

$$
\Delta Y S_{i}=\sum_{k=1}^{K} w_{i k} \Delta B o n d Y S_{i k}
$$

where $\Delta Y S_{i}$ is the portfolio yield spread change of insurer $i$ from 2005Q2 to 2005Q4, $\Delta$ BondY $S_{i k}$ is the yield spread change of bond $k$ in its portfolio over the same time period, $K$ is the number of sample bonds held by insurer $i$ at the end of 2004, and $w_{i k}$ is the weight of bond $k$ in its portfolio,

\footnotetext{
${ }^{21}$ We clean the data for cancellations, corrections, reversals and duplicate interdealer trade reporting following Dick-Nielsen (2014). We further exclude when-issued, locked-in, commission, and special-price-condition trades as well as trades that settle in more than 3 days. On each day, a bond's yield is the trade-size weighted average of yields throughout the day.
} 
using the par value held at the end of 2004 as the weight. We then construct an insurer pair's joint portfolio yield spread change as the weighted average of each insurer's portfolio yield spread change, using the par value of the bonds held by each insurer as the weight. Specifically,

$$
\Delta Y S_{i j}=w_{i} \Delta Y S_{i}+w_{j} \Delta Y S_{j}
$$

where $\Delta Y S_{i j}$ is the joint portfolio's yield spread change for the pair of insurers $i$ and $j$ from 2005Q2 to $2005 \mathrm{Q} 4$.

Given our previous findings, we expect that when faced with a liquidity shock, insurers with more similar portfolios will experience a larger drop in the price (or increase in yield) of their corporate bond holdings than other insurers. That is, we hypothesize that the relationship between a pair's joint portfolio yield spread change and the interaction term Similarity_I*Exposed will be positive and significant. Our specification also includes as controls the weighted average characteristics of the bonds held by the insurer pair measured on the last trade date in the quarter prior to the hurricanes. These include the weighted average number of trades in the two quarters prior to the hurricanes (Avg. Ln(Trades)), the weighted average natural logarithm of the bonds' issuance amount (Avg. Ln(Amount)), and the weighted average natural logarithm of the bond's years to maturity (Avg. Ln(Maturity)). We also control for insurer pair characteristics: joint size, portfolio concentration, and regulatory capital.

The estimation results are presented in Table 10. In columns (1) and (2), we find that the coefficient on the interaction term Similarity_ $I^{*}$ Exposed is positive and significant. This indicates that exposed pairs with more similar portfolios experience a larger increase in their joint portfolio's yield spread around the time of the hurricanes compared to other pairs. When examining only the sample of exposed insurers in column (3), we find that the increase in joint portfolio bond yield spread is greater, the more similar the pair's portfolios. The findings in this section provide evidence that the relationship between portfolio similarity and common sales has the potential to depress prices and affect the value of insurers' holdings. 


\section{Individual Insurer Portfolio Similarity}

In the previous sections, we provide strong evidence that pairwise portfolio similarity can predict an insurer pair's common sales and price impact. But in order for regulators to engage in the prudential supervision of insurers, they must be able to identify specific entities that may contribute to the asset liquidation channel of risk transmission. In this section, we propose a methodology that transforms the portfolio similarity of insurer pairs into a metric at the individual insurer level by averaging an insurer's portfolio similarity with all others in the industry. Specifically, for insurer $i$ at year-end $t$,

$$
\text { Similarity_Avg } g_{i t}=\frac{\sum_{j \neq i, j=1}^{J} \text { Similarity }_{i j t}}{J-1}
$$

where $J$ is the number of insurers. Depending on whether we use asset class or issuer pairwise portfolio similarity, we refer to this measure as average portfolio similarity at the asset class (Similarity_Avg_AC) or issuer (Similarity_Avg_I) level.

We hypothesize that an insurer with higher average portfolio similarity will sell more in common with other insurers. To test this hypothesis, we construct a measure of common sales at the individual insurer level as the sum of all its pairwise common sales with the other insurers in the sample. That is, for insurer $i$ in quarter $t$,

$$
\text { Common Sales_Aggr } r_{i, t}=\sum_{j \neq i, j=1}^{J} \text { Common Sales } i, j, t
$$

Analogously to average portfolio similarity, aggregate common sales are constructed at the asset class (Common Sales_Aggr_AC) or issuer (Common Sales_Aggr_I) level. We then regress this insurer-level measure of aggregate common sales on the insurer's prior year average portfolio similarity at the asset class or issuer level. ${ }^{22}$ We also control for the insurer's size (Size), concentration of holdings (Conc_AC or Conc_I), and line of business (PC and Life indicators).

The results are presented in Table 11 and indicate that an insurer's Similarity_Avg is strongly related to its subsequent aggregate common sales even after controlling for the size of the insurer. ${ }^{23}$ In other words, the more similar the portfolio holdings of a specific insurer to those of other insurers,

\footnotetext{
${ }^{22}$ Our results on average portfolio similarity remain robust if we use the average of the insurer's common sales.

${ }^{23}$ Our results are robust to using total net sales instead of size.
} 
the more that insurer contributes to common selling in the aggregate.

Overall, the results in this section suggest that the average portfolio similarity of an insurer conveys useful information about its common sales with other insurers even after controlling for other insurer characteristics such as size, total sales, concentration, and business line. Thus, such a measure could be used by regulators to identify systemically important insurers that are most likely to contribute to asset liquidation vulnerabilities.

\section{Conclusion}

Recent designations of insurers as systemically important presuppose that insurers holding similar assets have large common sales that could impact prices. We provide evidence consistent with this presumption.

First, we document that insurers' portfolios are indeed very similar. Using cluster analysis, we find that insurers follow a small number of investment strategies and that these strategies are relatively stable through time. Furthermore, in support of FSOC's particular concern over large insurers, we document that insurers that could be designated as SIFIs based on their size have higher average portfolio similarity than other insurers.

Second, we develop a novel measure of pairwise interconnectedness that focuses on insurers' portfolio similarity. We examine the measure's association with common selling and find that pairs of insurers that have greater portfolio similarity have larger subsequent common sales. This result holds across all insurer pairs regardless of potential SIFI status. We show that our measure of portfolio similarity predicts common selling even after incorporating a market measure of interconnectedness - stock return covariance - and considering the liquidity and credit quality of the portfolio. Furthermore, for certain insurers, regulatory capital constraints and periods of market stress magnify the relationship between portfolio similarity and common selling.

Third, we exploit the occurrence of Hurricanes Katrina and Rita to isolate the incidence of forced sales as opposed to anticipated portfolio rebalancing or trading motivated by changing security fundamentals. We find that in response to this exogenous liquidity shock, insurers with large exposures in hurricane-affected states have even greater common sales when they have greater portfolio similarity. Using corporate bond price information, we also show that these insurers' 
holdings experience a drop in value from the quarter before to the quarter after the hurricanes and that this drop is larger when exposed insurers have more similar portfolios.

Finally, we use the average portfolio similarity of an individual insurer with all others in the industry as a way to gage its potential to contribute to financial instability. We show that while insurer characteristics affect an insurer's aggregate common sales, its average portfolio similarity remains a significant predictor.

Overall, our results indicate that commonality in asset holdings captures important mechanics of the asset liquidation channel of risk transmission in the insurance industry. Specifically, the portfolio similarity measure we develop can predict the probability and magnitude of common selling of similar asset classes and similar issuers that may negatively affect prices. Furthermore, our measure captures similarity across the entirety of financial institutions' portfolios and does not require that institutions have publicly traded equity. Thus, we believe that our portfolio similarity measure can be used by regulators to predict the common selling of any institution that reports security or asset class level holdings. 


\section{References}

Allen, F., Babus, A., Carletti, E., 2012. Asset commonality, debt maturity and systemic risk. Journal of Financial Economics 104, 519-534.

Billio, M., Getmansky, M., Lo, A. W., Pelizzon, L., 2012. Econometric measures of connectedness and systemic risk in the finance and insurance sectors. Journal of Financial Economics 104, $535-559$.

BIS, 2014. The G-SIB assessment methodology - score calculation, working paper available at http://www.bis.org/bcbs/publ/d296.htm.

Brunetti, C., Harris, J. H., Mankad, S., Michailidis, G., 2015. Interconnectedness in the interbank market, working paper available at https://ssrn.com/abstract=2674602.

Castiglionesi, F., Navarro, N., 2008. Optimal fragile financial networks, working paper available at http://ssrn.com/abstract $=1089357$.

Chaderina, M., Muermann, A., Scheuch, C., 2018. The dark side of liquid bonds in fire sales, working paper available at https://ssrn.com/abstract $=2995544$.

Chiang, C.-C., Niehaus, G., 2016. Investment herding by life insurers and its impact on bond prices, working paper available from authors.

Cont, R., Schaanning, E., 2018. Monitoring indirect contagion.

Cont, R., Wagalath, L., 2016. Institutional investors and the dependence structure of asset returns. International Journal of Theoretical and Applied Finance 19, 10-47.

Cummins, J. D., Weiss, M. A., 2014. Systemic risk and the U.S. insurance sector. Journal of Risk and Insurance 81, 489-528.

Dick-Nielsen, J., 2014. How to clean Enhanced TRACE data, working paper available at https://ssrn.com/abstract $=2337908$.

Dunn, J. C., 1974. Well-separated clusters and optimal fuzzy partitions. Journal of Cybernetics 4, 95-104.

Ellul, A., Jotikasthira, C., Lundblad, C. T., 2011. Regulatory pressure and fire sales in the corporate bond market. Journal of Financial Economics 101, 596-620.

Ellul, A., Jotikasthira, C., Lundblad, C. T., Wang, Y., 2015. Is historical cost accounting a panacea? Market stress, incentive distortions, and gains trading. Journal of Finance 70, 2489-2538.

Fang Cai, Han, S., Li, D., Li, Y., 2018. Institutional herding and its price impact: Evidence from the corporate bond market, forthcoming Journal of Financial Economics.

FSOC, 2013. Basis for the Financial Stability Oversight Council's final determination regarding Prudential Financial, Inc., available at https://www.treasury.gov/initiatives/fsoc/designations.

Gai, P., Haldane, A., Kapadia, S., 2011. Complexity, concentration and contagion. Journal of Monetary Economics 58, 453-470. 
Geneva Association, T., 2010. Systemic risk in insurance: An analysis of insurance and financial stability. Special Report of the Geneva Association Systemic Risk Working Group .

Grace, M. F., 2010. The insurance industry and systemic risk: Evidence and discussion, working paper available at https://ssrn.com/abstract $=1593645$.

Haldane, A. G., May, R. M., 2011. Systemic risk in banking ecosystems. Nature 469, 351-355.

Handl, J., Knowles, J., Kell, D. B., 2005. Computational cluster validation in post-genomic data analysis. Bioinformatics 21, 3201-3212.

Hanley, K. W., Hoberg, G., 2010. The information content of IPO prospectuses. Review of Financial Studies 23, 2821-2864.

Hanley, K. W., Hoberg, G., 2012. Litigation risk, strategic disclosure and the underpricing of initial public offerings. Journal of Financial Economics 103, 235-254.

Hanley, K. W., Nikolova, S., 2017. Rethinking the use of credit ratings in capital regulation, working paper available at http://ssrn.com/abstract $=2357145$.

Harrington, S. E., 2009. The financial crisis, systemic risk, and the future of insurance regulation. Journal of Risk and Insurance 76, 785-819.

Ibragimov, R., Jaffee, D., Walden, J., 2011. Diversification disasters. Journal of Financial Economics $99,333-348$.

Jian Cai, Eidam, F., Saunders, A., Steffen, S., 2018. Syndication, interconnectedness, and systemic risk. Journal of Financial Stability 34, 105-120.

Kartasheva, A., 2014. Insurance in the financial system, bIS working paper.

Khandani, A. E., Lo, A. W., 2011. What happened to the quants in august 2007? Evidence from factors and transactions data. Journal of Financial Markets 14, 1-46.

Koijen, R. S. J., Yogo, M., 2016. Shadow insurance. Econometrica 84, 1265-1287.

Liu, M., 2016. Strategic liquidity hoarding and predatory trading: An empirical investigation, u.

MacQueen, J., 1967. Some methods for classification and analysis of multivariate observations. Proceedings of the fifth Berkeley symposium on mathematical statistics and probability 1, 281297.

Manconi, A., Massa, M., Yasuda, A., 2012. The role of institutional investors in propagating the crisis of 2007-2008. Journal of Financial Economics 104, 491-518.

Manconi, A., Massa, M., Zhang, L., 2016. Bondholder concentration and credit risk: Evidence from a natural experiment. Review of Finance 20, 127-159.

Merrill, C. B., Nadauld, T., Stulz, R. M., Sherlund, S. M., 2013. Why were there fire sales of mortgage-backed securities by financial institutions during the financial crisis?, working paper available at http://ssrn.com/abstract $=2212684$.

Nanda, V., Wu, W., Zhou, Z., 2017. Insurer investment commonality: Fire sale risk and corporate yield spreads, working paper. 
Neale, F. R., Drake, P. P., Schorno, P., Semann, E., 2012. Insurance and interconnectedness in the financial services industry, working paper.

Rousseeuw, P. J., 1987. Silhouettes: A graphical aid to the interpretation and validation of cluster analysis. Journal of Computational and Applied Mathematics 20, 53-65.

Sias, R., Turtle, J., Zykaj, B., 2016. Hedge fund crowds and mispricing. Management Science 62, $764-784$.

Wagner, W., 2010. Diversification at financial institutions and systemic crises. Journal of Financial Intermediation 19, $373-386$.

Wagner, W., 2011. Systemic liquidation risk and the diversity diversification trade-off. The Journal of Finance 66, 1141-1175. 


\section{Appendix A: Asset Classes}

Asset-backed securities (other than CMBS and RMBS)

Commercial mortgage-backed securities (CMBS)

Corporate bonds: Banks

Corporate bonds: Basic materials, durables, cyclicals

Corporate bonds: Consumer staples, retail

Corporate bonds: Energy

Corporate bonds: Financials not further defined

Corporate bonds: Health

Corporate bonds: Insurers

Corporate bonds: Not further defined

Corporate bonds: Pharmaceutical, chemical

Corporate bonds: Services

Corporate bonds: Technology

Corporate bonds: Utilities

Equity: Banks

Equity: Basic materials, durables, cyclicals

Equity: Consumer staples, retail

Equity: Energy

Equity: Financials not further defined

Equity: Government-sponsored entity

Equity: Health

Equity: Insurers

Equity: Not further defined

Equity: Pharmaceutical, chemical

Equity: Services

Equity: Technology

Equity: Utilities

Government-sponsored entity debt securities

Municipal bonds: General obligation

Municipal bonds: Revenue and other non-general obligation

Mutual fund shares

Residential mortgage-backed securities (RMBS)

Sovereign bonds

U.S. government securities (including securities issued by all federal agencies) 


\section{Appendix B: Variable Definitions}

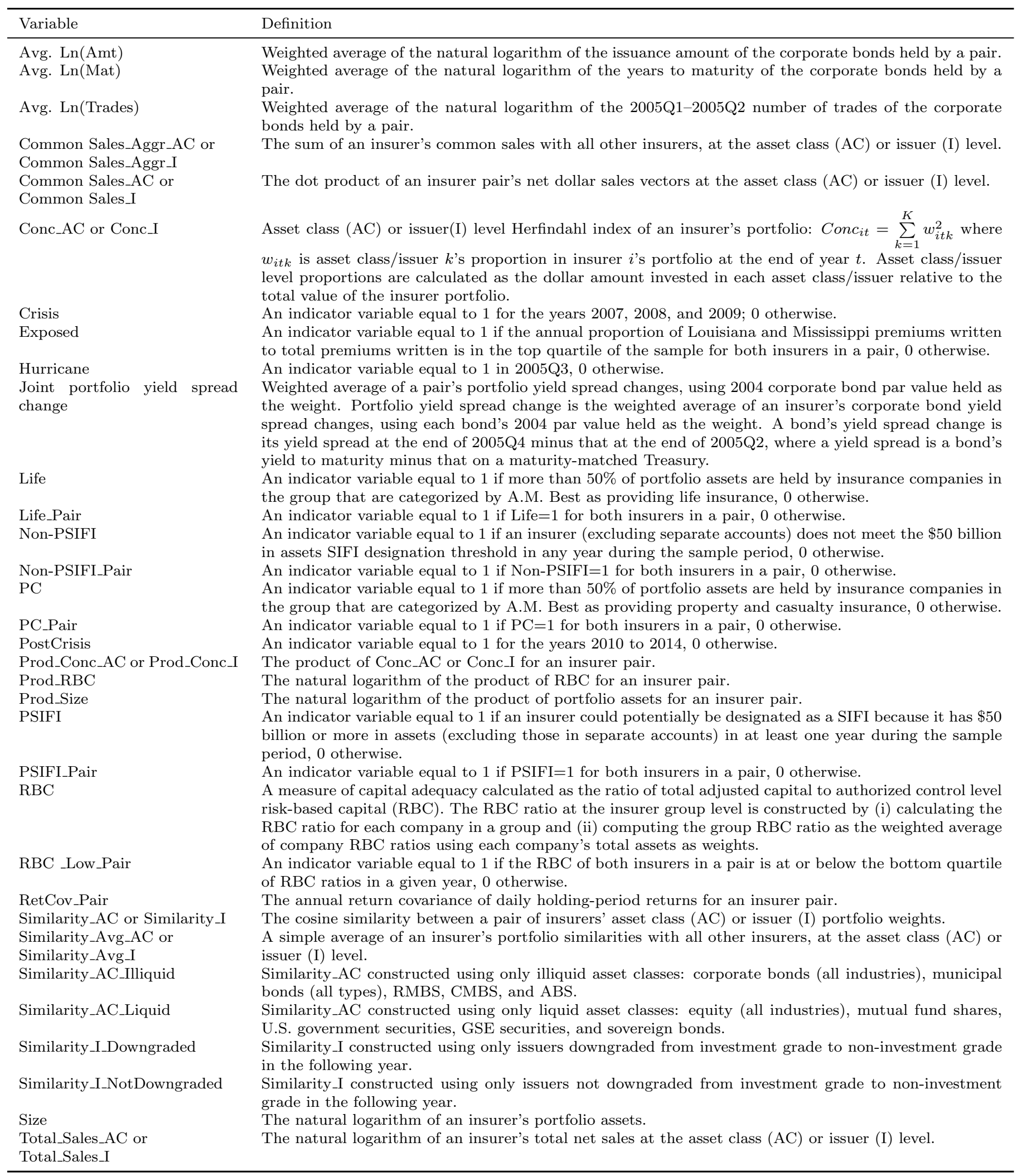




\section{Appendix C: Cluster Analysis}

\section{Cluster Algorithm}

Cluster analysis could be performed using several algorithms that differ significantly in their notion of what constitutes a cluster and how to efficiently find clusters. The approach used in our paper is largely based on the concept that clusters are groups with small distances among the cluster members with particular statistical distributions. As described in more detail below, we apply internal validation measures, namely Dunn Index (Dunn, 1974), Silhouette Width (Rousseeuw, 1987) and Connectivity (Handl et al., 2005), on the most utilized unsupervised clustering algorithms (Self Organizing Maps, Self Organizing Tree Maps, K-means, and hierarchical).

The optimal number of clusters $\left(N_{\text {opt }}\right)$ is finally obtained by computing the mode of the optimal number of clusters across the 13 years of our sample $\left(N_{t}\right)$.

$$
N_{o p t}=M o\left(N_{t}\right)
$$

Coherently, the optimal algorithm $\left(C_{\text {opt }}\right)$ is derived by counting the number of times an algorithm appears as locally optimal over the 13 years $\left(C_{t}\right)$ and selecting the maximum value.

$$
C_{\text {opt }}=\operatorname{Max}\left(\sum_{i=1}^{13} C_{t}\right)
$$

We run the unsupervised K-means algorithm (MacQueen, 1967) yearly with the following setting: 24

i) for the first year $\left(Y_{t}\right.$ with $\left.t=1\right)$ the number of clusters is 3 ;

ii) for the following year $\left(Y_{t}\right.$ with $\left.t=[2: 13]\right)$ the centroids are obtained from the cluster of the previous year $\left(Y_{t-1}\right)$.

The constraint for the cluster number in the first year comes from the outcome of the validation step. The constraint for the centroids' structure in the other years is set to introduce a short-time

\footnotetext{
${ }^{24}$ The algorithm is based on a finite number of cycles aimed at defining the optimal cluster centroids according to the minimization of the distance of the $n$ data points from their respective cluster centers, represented by the following objective function: $J=\sum_{j=1}^{k} \sum_{i=1}^{n}\left\|x_{i}^{j}-c_{j}\right\|^{2}$ where $x_{i}^{j}$ is a data point and $c_{j}$ is the cluster center.
} 
memory effect in the evolution of the clusters over time. The link of the cluster structures over time allows us to observe the transition of insurers among clusters year by year.

We then analyze the clusters by examining:

i) their size, both in term of the number of insurers and the dollar value of insurers' assets;

ii) their centroids' structure;

iii) the transition of insurers among clusters over time.

The average structure of the 3 clusters' centroids $\left(\overline{x^{i}}\right)$ is computed as the average over time of the centroids' components $\left(x_{t}^{i}\right)$.

$$
\overline{x^{i}}=\frac{1}{13} \sum_{t=1}^{13}\left(x_{t}^{i}\right)
$$

Finally the yearly net flow $\left(\right.$ NetFlow $\left._{i}\right)$ for cluster $i$ is computed as:

$$
\text { Flow }_{i t}=\sum_{j \neq i} I_{j t} I n-\sum_{j=i} I_{j t} O u t
$$

The cluster validation process applied to the yearly dataset provides the best fitting algorithm for the number of clusters. Each validation methodology is applied yearly using K-means algorithm. The optimal number of clusters appears to be $3 .^{25}$

\section{Cluster Validation}

To validate the cluster approach we select a set of measures that reflect the degree of compactness, connectedness, and separation of the cluster partitions, tested respectively with Connectivity, Dunn Index and Silhouette Width, respectively.

Connectivity (Handl et al., 2005): Connectivity estimates to what extent the nearest observations (in our case insurers) are placed in the same cluster. We define $N$ as the number of observations in the sample, $M$ as the number of attributes of each observation (namely the coordinates of the observation in an M-dimensional space), and $n n_{i(j)}$ as the $j^{\text {th }}$ nearest neighbor of

\footnotetext{
${ }^{25}$ Details on the validation are provided upon request.
} 
observation $i$. Let $x_{i, n n_{i(j)}}$ be

$$
x_{i, n n_{i(j)}}= \begin{cases}0, & \text { if } i \text { and } j \text { are in the same cluster } \\ \frac{1}{j}, & \text { otherwise }\end{cases}
$$

For a specific cluster partition $\mathcal{C}=\left\{C_{1}, \ldots C_{k}\right\}$ of the $N$ observations, connectivity is defined as:

$$
\operatorname{Conn}(\mathcal{C})=\sum_{i=1}^{N} \sum_{j=1}^{L} x_{i, n n_{i(j)}}
$$

where $L$ is the number of neighbors used. Connectivity has values between 0 and $\infty$ and should be minimized.

Silhouette Width (Rousseeuw, 1987): Silhouette Width is the average of each observation's Silhouette Value. Silhouette Value is defined as:

$$
S(i)=\frac{b_{i}-a_{i}}{\max \left(b_{i}, a_{i}\right)}
$$

where $a_{i}$ is the average distance between observation $i$ and the other observations belonging to the same cluster, and $b_{i}$ is the average distance between $i$ and the observations in the "nearest neighboring " cluster defined as:

$$
b_{i}=\min _{C_{k} \in \mathcal{C} C(i)} \sum_{j \in C_{k}} \frac{\operatorname{dist}(i, j)}{n\left(C_{k}\right)}
$$

where $C(i)$ is the cluster containing observation $i, \operatorname{dist}(i, j)$ is the distance between observations $i$ and $j$, and $n(C)$ is the cardinality of cluster $C$. Silhouette Width lies in the $[-1,1]$ range and should be maximized.

Dunn Index (Dunn, 1974): Dunn Index is the ratio of the smallest distance between observations not in the same cluster and the largest intra-cluster distance:

$$
D(\mathcal{C})=\frac{\min _{C_{k}, C_{l} \in \mathcal{C}, C(k) \neq C_{l}}\left(\min _{i \in C_{k}, j \in C_{j}} \operatorname{dist}(i, j)\right)}{\max _{C_{m} \in \mathcal{C}} \operatorname{diam}\left(C_{m}\right)}
$$


where $\operatorname{diam}\left(C_{m}\right)$ is the maximum distance between observations in cluster $C_{m}$. Dunn Index is in the $[0, \infty]$ range and should be maximized. 
Figure 1: Portfolio Composition Through Time

This figure presents the composition of the aggregate insurance industry portfolio by primary asset class from 2002 to 2014 .

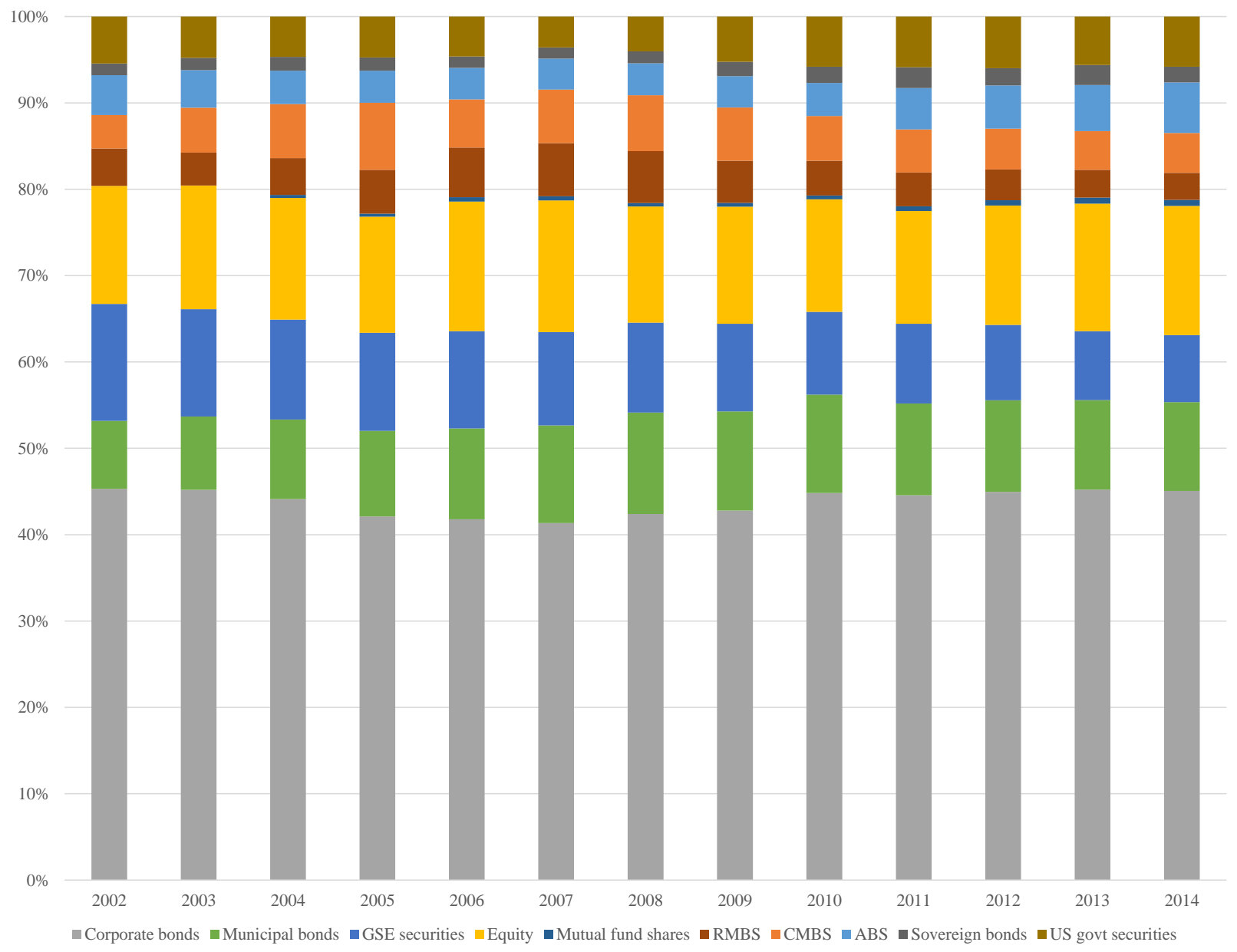


Figure 2: Portfolio Cluster Composition by Primary Asset Classes

This figure presents the average primary asset class dollar composition of the three clusters of insurer portfolios from 2002 to 2014 .

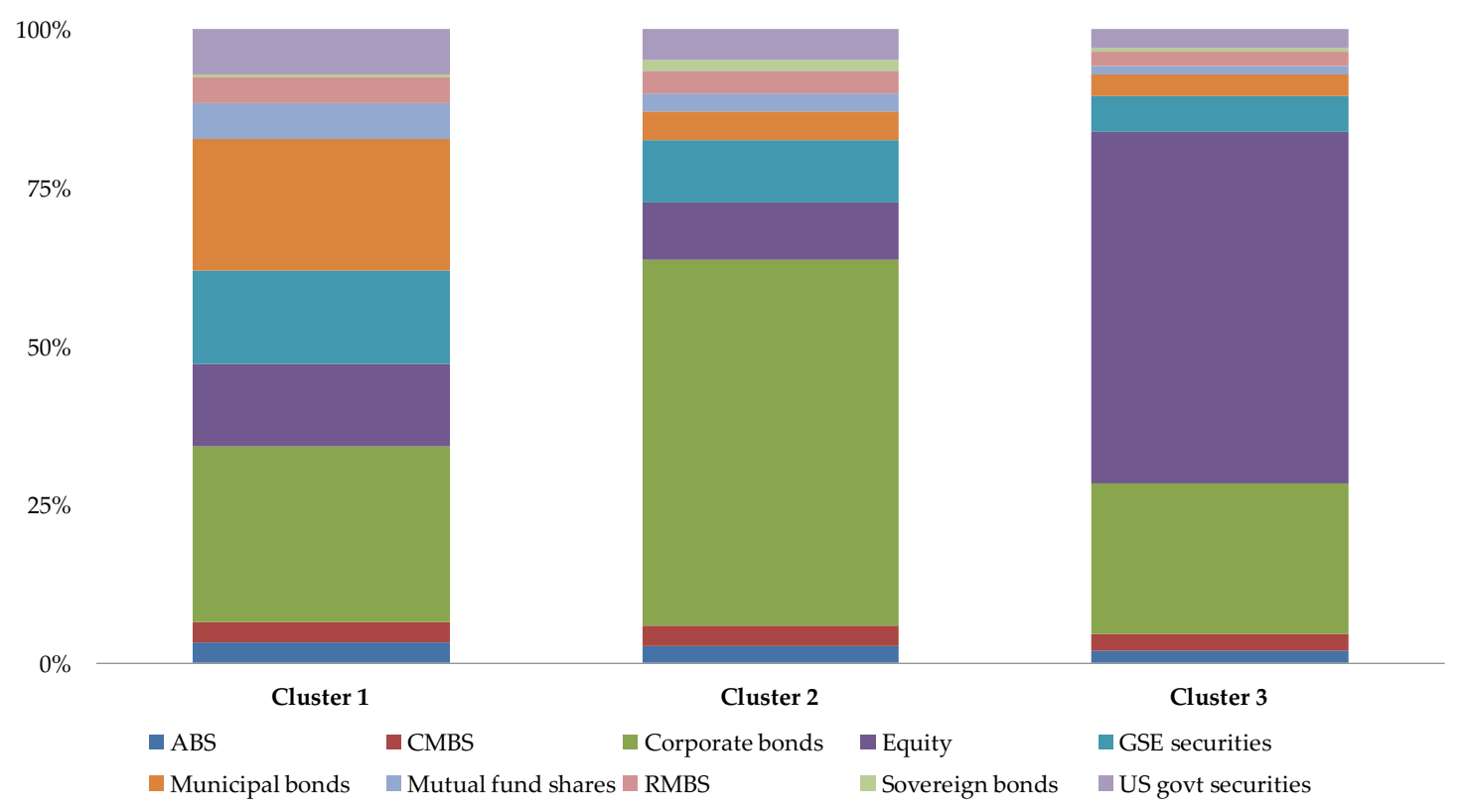


Figure 3: Distribution of PSIFIs and Non-PSIFIs in Portfolio Clusters

The figures present the distribution of PSIFI and non-PSIFI insurers among the three clusters from 2002 to 2014. PSIFI is an insurer that could potentially be designated a SIFI because it has $\$ 50$ billion or more in assets (excluding those in separate accounts) in at least one year during the sample period. Non-PSIFI is an insurer that does not meet the PSIFI definition.

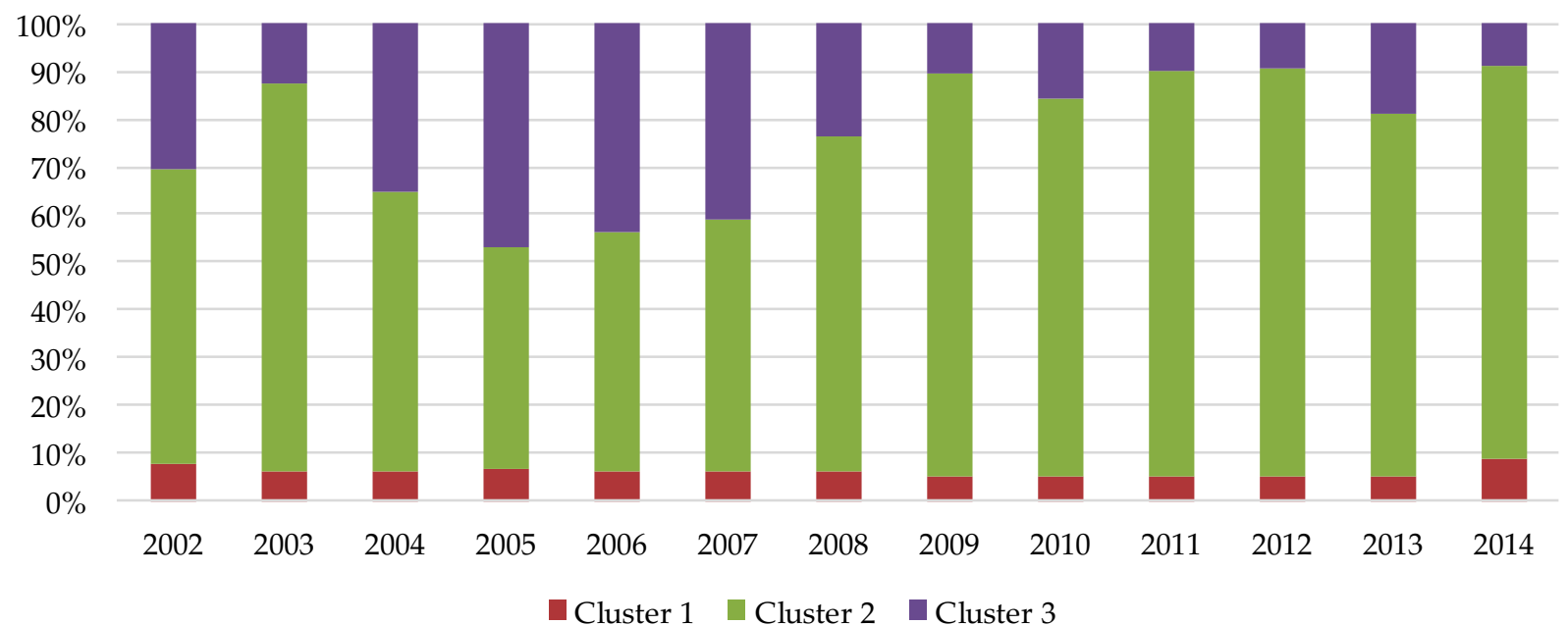

(a) PSIFI

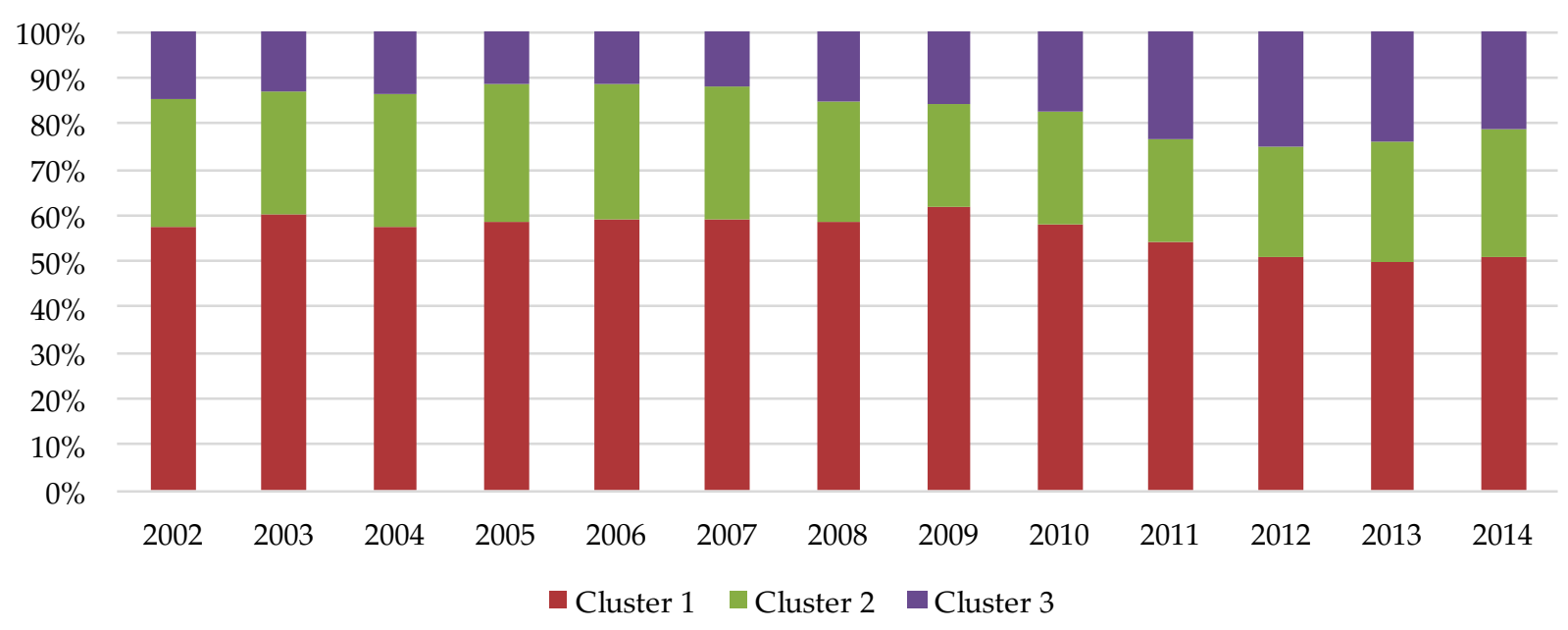

(b) Non-PSIFI 
Figure 4: Portfolio Similarity Through Time

The figure presents average portfolio similarity at the (a) asset class level (Similarity_AC) and (b) issuer level (Similarity_I) from 2002 to 2014. PSIFI is an insurer that could potentially be designated a SIFI because it has $\$ 50$ billion or more in assets (excluding those in separate accounts) in at least one year during the sample period. Non-PSIFI is an insurer that does not meet the PSIFI definition. PSIFI (non-PSIFI) pairs are those where both insurers in the pair are classified as PSIFI (non-PSIFI).

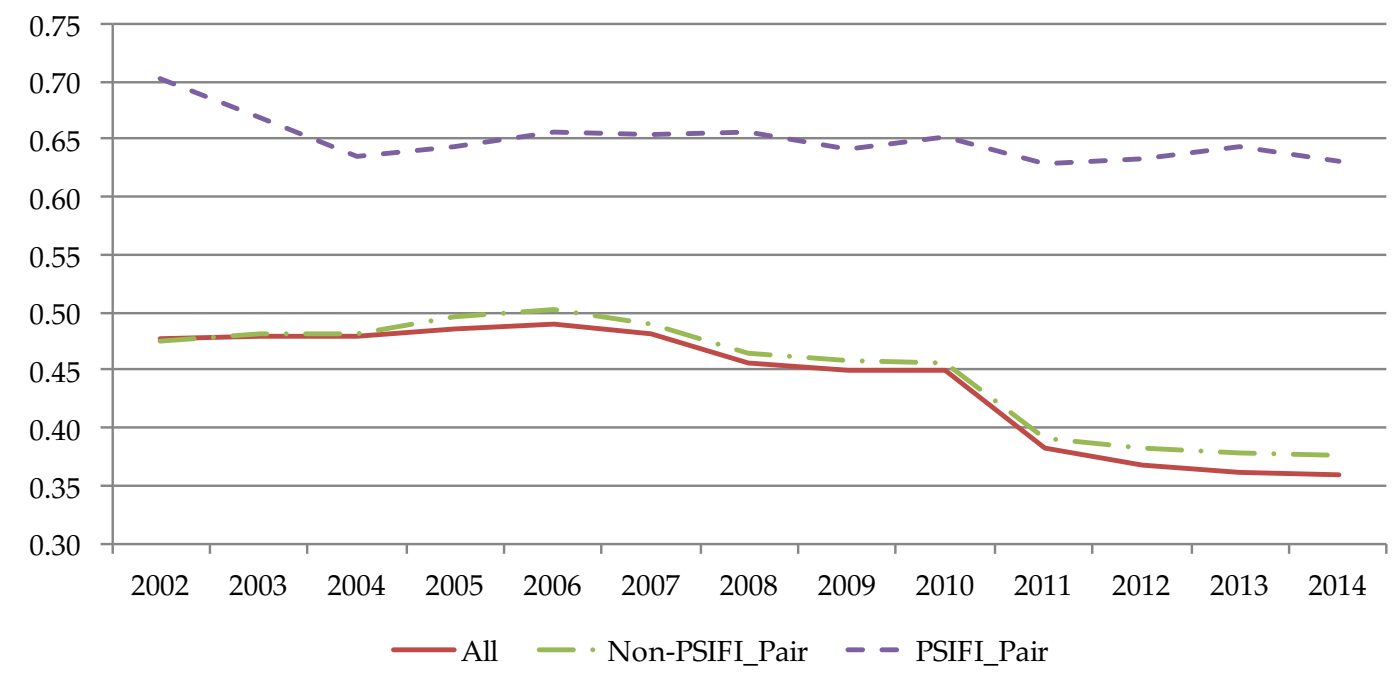

(a) Portfolio Similarity at the Asset Class Level

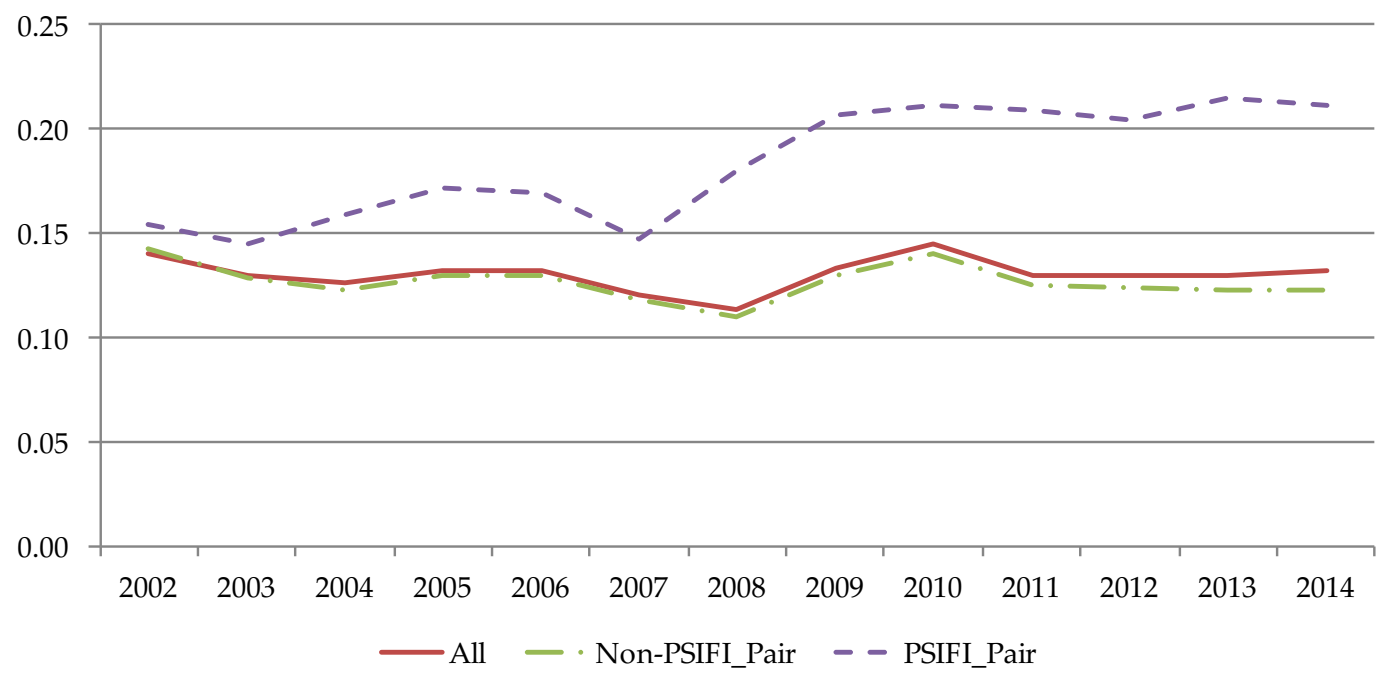

(b) Portfolio Similarity at the Issuer Level 
Figure 5: Proportion of Illiquid and Downgraded Holdings

The figures present the proportion of holdings that are composed of (a) illiquid asset classes or (b) downgraded issuers from 2002 to 2014. Illiquid asset classes include corporate bonds (all industries), municipal bonds (all types), RMBS, CMBS, and ABS. Downgraded issuers are those that are downgraded from investment grade to non-investment grade in the following year.

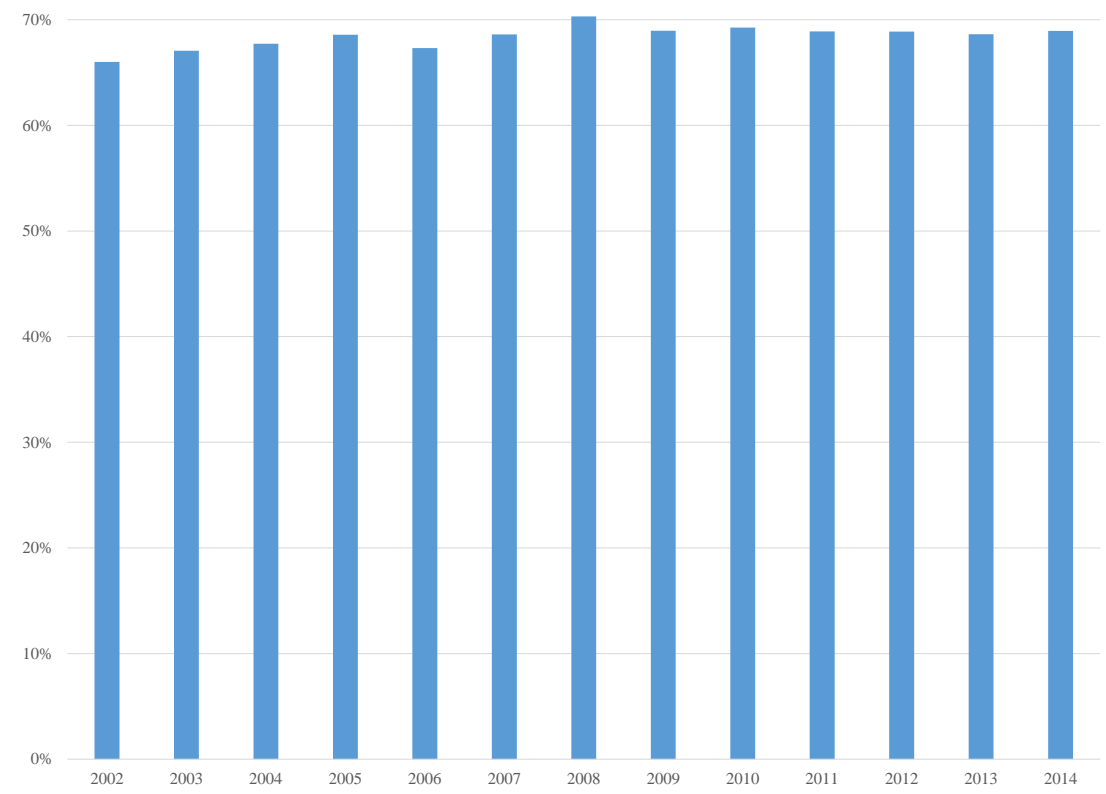

(a) Illiquid Asset Classes

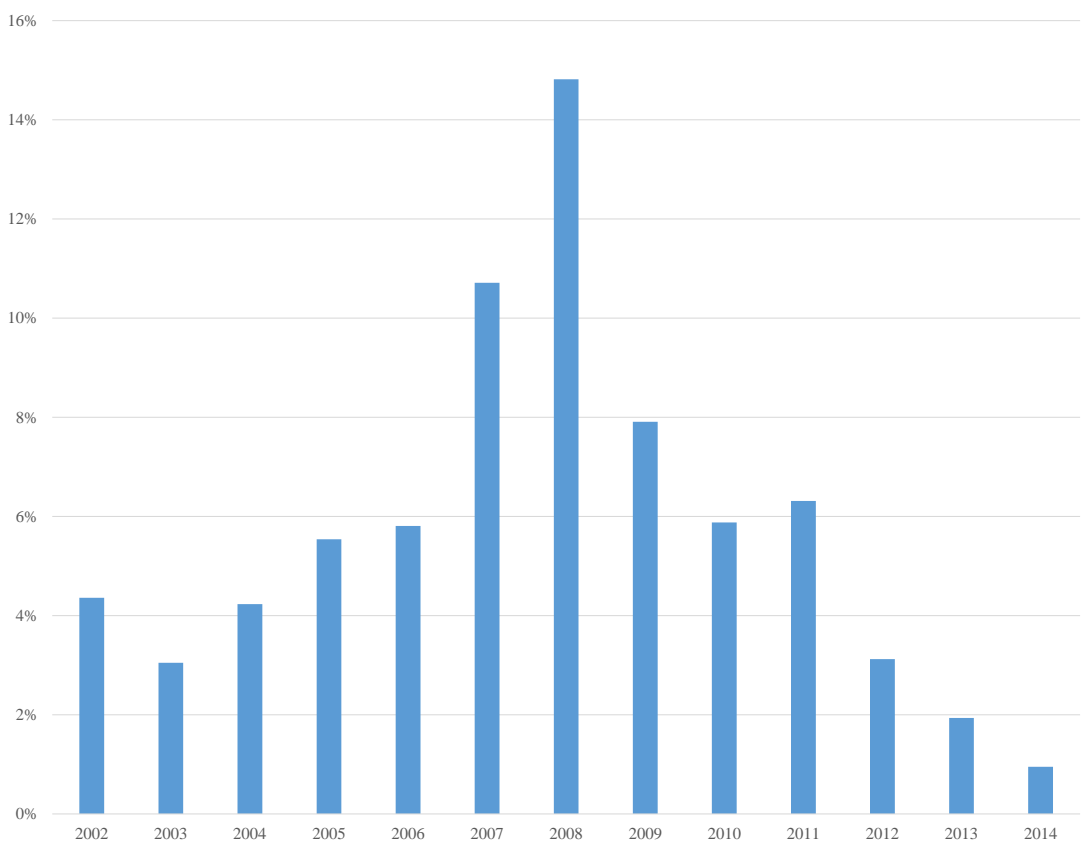

(b) Downgraded Issuers 
Figure 6: Common Sales Through Time

The figures present the average of the natural logarithm of one plus quarterly common sales at the (a) asset class level (Common Sales_AC) or (b) issuer level (Common Sales_I) from 2002 to 2014. PSIFI is an insurer that could potentially be designated a SIFI because it has $\$ 50$ billion or more in assets (excluding those in separate accounts) in at least one year during the sample period. Non-PSIFI is an insurer that does not meet the PSIFI definition. PSIFI (non-PSIFI) pairs are those where both insurers in the pair are classified as PSIFI (non-PSIFI).

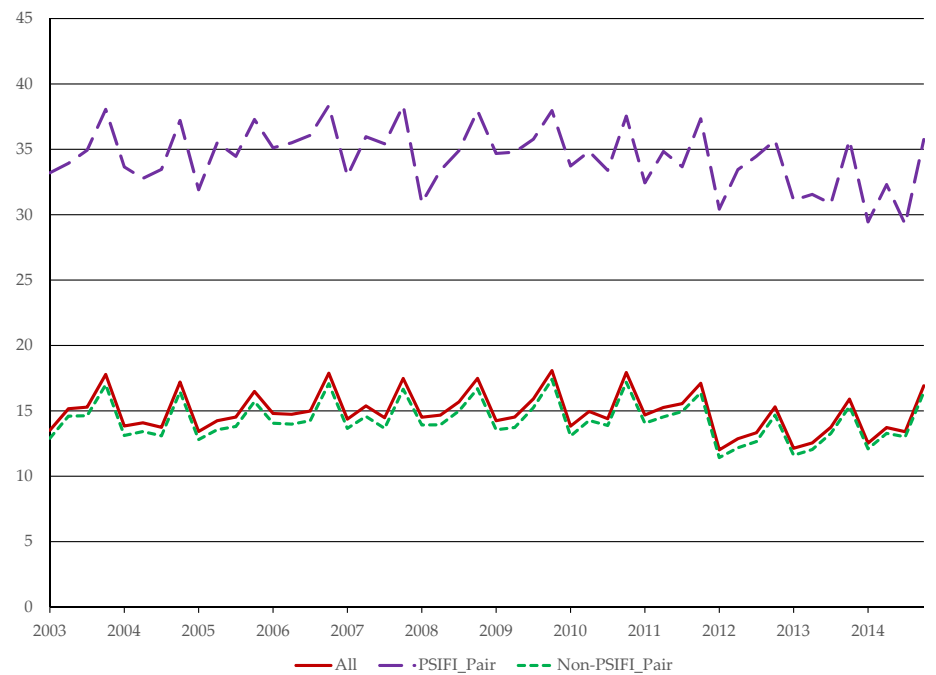

(a) Common Sales at the Asset Class Level

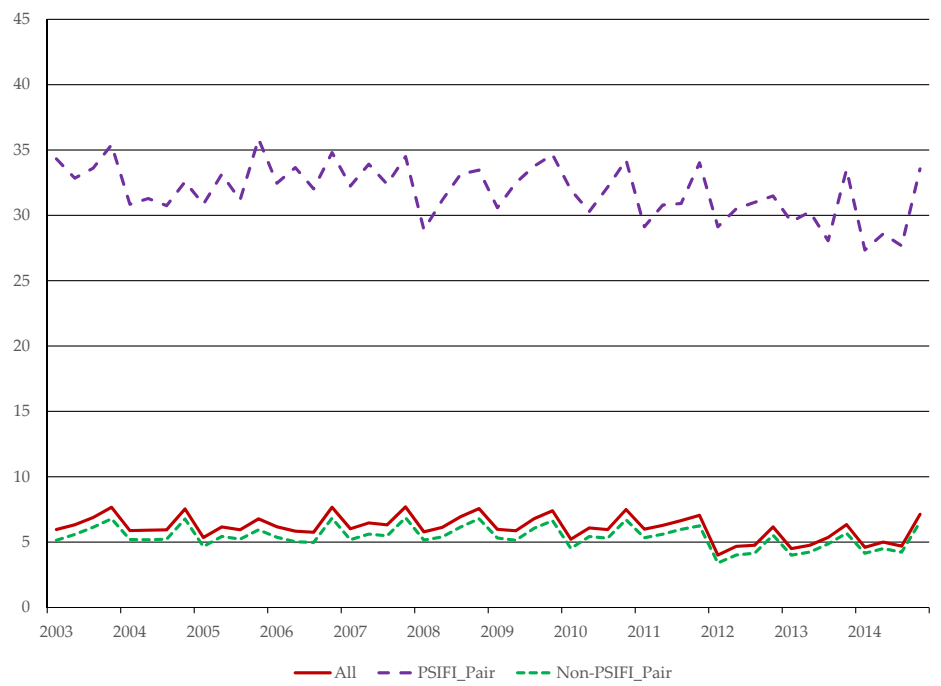

(b) Common Sales at the Issuer Level 


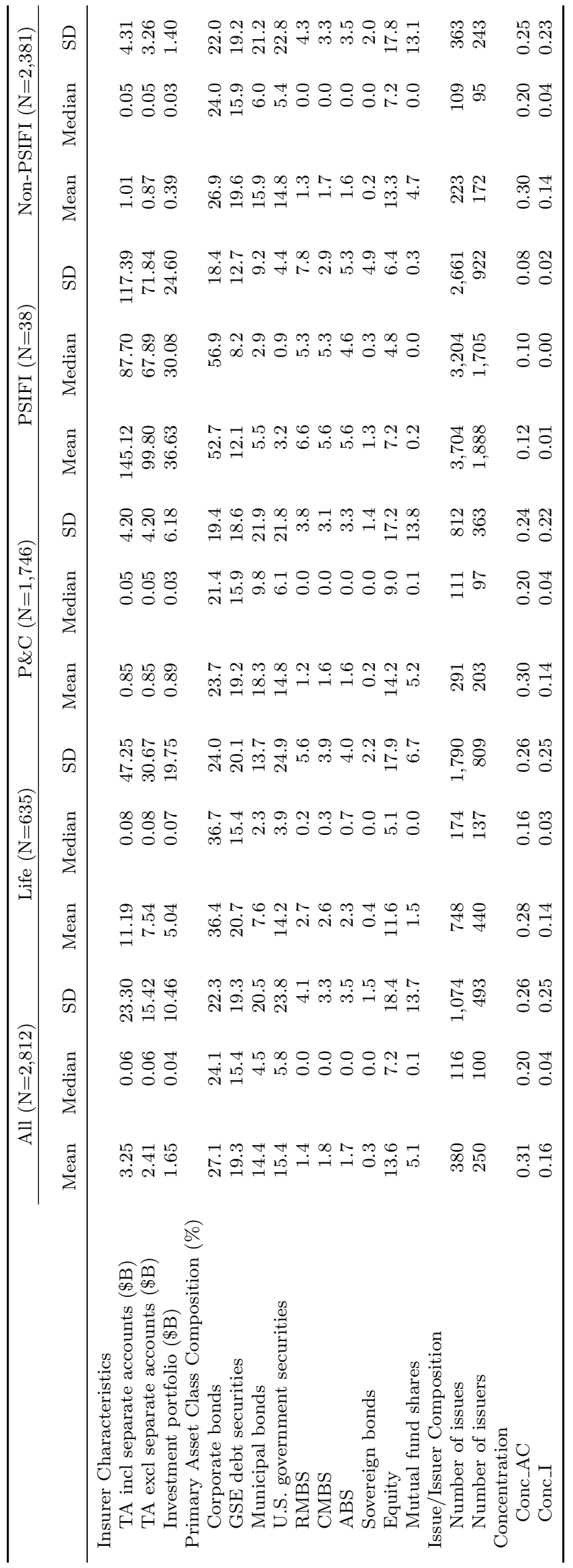




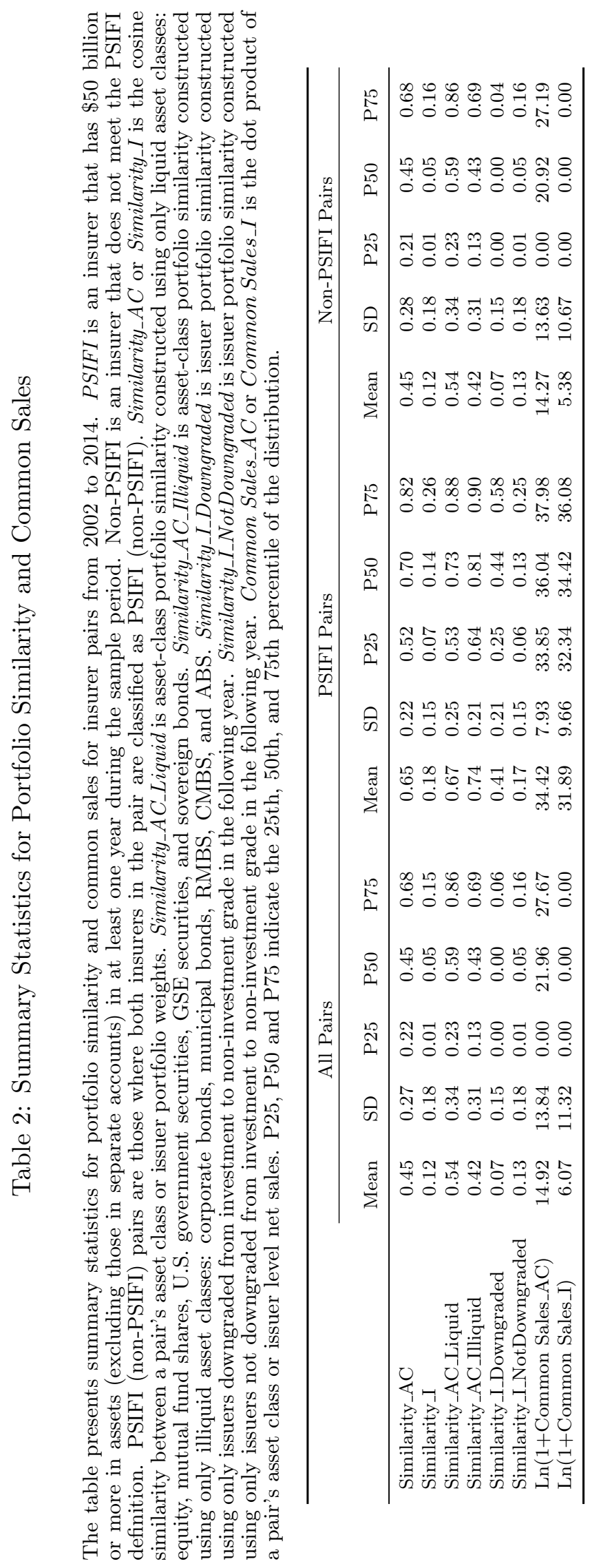




\section{Table 3: Determinants of Portfolio Similarity}

The table presents OLS estimation results for the sample of insurer pairs from 2002 to 2014. The dependent variable is Similarity_AC or Similarity_I, defined as the cosine similarity between a pair's asset class or issuer portfolio weights. Life_Pair is an indicator variable equal to 1 if both insurers in a pair are life insurers, 0 otherwise. $P C_{-} P a i r$ is an indicator variable equal to 1 if both insurers in a pair are P\&C insurers, 0 otherwise. PSIFI_Pair is an indicator variable equal to 1 if both insurers in a pair have $\$ 50$ billion or more in assets (excluding those in separate accounts) in at least one year during the sample period, 0 otherwise. Non-PSIFI_Pair is an indicator variable equal to 1 if both insurers do not meet the PSIFI definition, 0 otherwise. Prod_Size is the natural logarithm of the product of a pair's portfolio assets. Prod_Conc_AC or Prod_Conc_I is the product of a pair's portfolio Herfindahl indices at the asset class or issuer level. Robust $t$-statistics are in parentheses. Statistical significance is denoted by $* * *, * *$, and $*$ at the $1 \%, 5 \%$, and $10 \%$ level respectively.

\begin{tabular}{|c|c|c|c|c|c|c|}
\hline & \multicolumn{3}{|c|}{ Portfolio Similarity - Asset Class } & \multicolumn{3}{|c|}{ Portfolio Similarity - Issuer } \\
\hline & $\begin{array}{c}\text { All } \\
\text { Pairs } \\
(1)\end{array}$ & $\begin{array}{l}\text { PSIFI } \\
\text { Pairs } \\
(2)\end{array}$ & $\begin{array}{c}\text { Non-PSIFI } \\
\text { Pairs } \\
(3)\end{array}$ & $\begin{array}{l}\text { All } \\
\text { Pairs } \\
(4)\end{array}$ & $\begin{array}{c}\text { PSIFI } \\
\text { Pairs } \\
(5)\end{array}$ & $\begin{array}{l}\text { Non-PSIFI } \\
\text { Pairs } \\
(6)\end{array}$ \\
\hline Life_Pair & $\begin{array}{l}0.058^{* * *} \\
(8.06)\end{array}$ & $\begin{array}{l}0.183^{* * *} \\
(21.48)\end{array}$ & $\begin{array}{l}0.051^{* * *} \\
(6.50)\end{array}$ & $\begin{array}{l}-0.005^{* * *} \\
(-3.51)\end{array}$ & $\begin{array}{l}0.027^{* * *} \\
(3.69)\end{array}$ & $\begin{array}{l}-0.006^{* * *} \\
(-4.33)\end{array}$ \\
\hline PC_Pair & $\begin{array}{l}0.035^{* * *} \\
(8.20)\end{array}$ & $\begin{array}{l}0.087^{* * *} \\
(7.16)\end{array}$ & $\begin{array}{l}0.033^{* * *} \\
(7.42)\end{array}$ & $\begin{array}{l}0.028^{* * *} \\
(22.10)\end{array}$ & $\begin{array}{l}0.035^{* *} \\
(2.30)\end{array}$ & $\begin{array}{l}0.028^{* * *} \\
(20.34)\end{array}$ \\
\hline PSIFI_Pair & $\begin{array}{l}0.086^{* * *} \\
(13.63)\end{array}$ & & & $\begin{array}{l}0.051^{* * *} \\
(15.03)\end{array}$ & & \\
\hline NonPSIFI_Pair & $\begin{array}{l}0.127^{* * *} \\
(25.68)\end{array}$ & & & $\begin{array}{l}0.017^{* * *} \\
(4.65)\end{array}$ & & \\
\hline Prod_Size & $\begin{array}{l}0.016^{* * *} \\
(24.50)\end{array}$ & $\begin{array}{l}-0.020 * * * \\
(-3.55)\end{array}$ & $\begin{array}{l}0.015^{* * *} \\
(23.29)\end{array}$ & $\begin{array}{l}0.003^{* * *} \\
(6.01)\end{array}$ & $\begin{array}{l}0.005 \\
(1.03)\end{array}$ & $\begin{array}{l}0.003^{* * *} \\
(5.72)\end{array}$ \\
\hline Prod_Conc_AC & $\begin{array}{l}-0.333^{* * *} \\
(-16.71)\end{array}$ & $\begin{array}{l}-22.250^{* * *} \\
(-8.73)\end{array}$ & $\begin{array}{l}-0.330 * * * \\
(-16.64)\end{array}$ & & & \\
\hline Prod_Conc_I & & & & $\begin{array}{l}0.579 * * * \\
(14.64)\end{array}$ & $\begin{array}{l}-111.707^{* * *} \\
(-7.12)\end{array}$ & $\begin{array}{l}0.577^{* * *} \\
(14.69)\end{array}$ \\
\hline Year FE & YES & YES & YES & YES & YES & YES \\
\hline$N$ & $10,605,950$ & 6,608 & $10,078,140$ & $10,605,950$ & 6,608 & $10,078,140$ \\
\hline $\operatorname{Adj} R^{2}$ & 0.106 & 0.436 & 0.104 & 0.029 & 0.064 & 0.029 \\
\hline
\end{tabular}




\section{Table 4: Portfolio Similarity as a Determinant of Common Sales}

The table presents probit/tobit estimation results for the sample of insurer pairs from 2002 to 2014 . In columns (1) and (5), the dependent variable is an indicator variable equal to 1 if the natural logarithm of one plus Common Sales_AC or Common Sales_I, defined as the dot product of a pair's asset class or issuer net sales, is positive, 0 otherwise. In columns (2)-(4) and (6)-(8), the dependent variable is the natural logarithm of one plus Common Sales_AC or Common Sales_I. Similarity_AC or Similarity_I is the cosine similarity between a pair's asset class or issuer portfolio weights. The remaining independent variables are defined in Appendix B. All independent variables are measured as of the year-end prior to the sales quarter. Robust $t$-statistics are in parentheses. Statistical significance is denoted by $* * *, * *$, and $*$ at the $1 \%, 5 \%$, and $10 \%$ level respectively.

\begin{tabular}{|c|c|c|c|c|c|c|c|c|}
\hline & \multicolumn{4}{|c|}{ Common Sales - Asset Class } & \multicolumn{4}{|c|}{ Common Sales - Issuer } \\
\hline & $\begin{array}{l}\text { All } \\
\text { Pairs } \\
\text { Probit } \\
(1)\end{array}$ & $\begin{array}{l}\text { All } \\
\text { Pairs } \\
\text { Tobit } \\
(2)\end{array}$ & $\begin{array}{c}\text { PSIFI } \\
\text { Pairs } \\
\text { Tobit } \\
(3)\end{array}$ & $\begin{array}{c}\text { Non-PSIFI } \\
\text { Pairs } \\
\text { Tobit } \\
(4)\end{array}$ & $\begin{array}{c}\text { All } \\
\text { Pairs } \\
\text { Probit } \\
(5)\end{array}$ & $\begin{array}{l}\text { All } \\
\text { Pairs } \\
\text { Tobit } \\
(6)\end{array}$ & $\begin{array}{l}\text { PSIFI } \\
\text { Pairs } \\
\text { Tobit } \\
(7)\end{array}$ & $\begin{array}{c}\text { Non-PSIFI } \\
\text { Pairs } \\
\text { Tobit } \\
(8)\end{array}$ \\
\hline Similarity_AC & $\begin{array}{l}0.244^{* * *} \\
(28.61)\end{array}$ & $\begin{array}{l}4.714^{* * *} \\
(24.51)\end{array}$ & $\begin{array}{l}4.640^{* * *} \\
(7.38)\end{array}$ & $\begin{array}{l}4.969^{* * *} \\
(24.52)\end{array}$ & & & & \\
\hline Similarity_I & & & & & $\begin{array}{l}1.101^{* * * *} \\
(44.31)\end{array}$ & $\begin{array}{l}33.981^{* * *} \\
(40.48)\end{array}$ & $\begin{array}{l}17.628^{* * *} \\
(19.87)\end{array}$ & $\begin{array}{l}34.629 * * * \\
(39.48)\end{array}$ \\
\hline Life_Pair & $\begin{array}{l}-0.124^{* * *} \\
(-14.64)\end{array}$ & $\begin{array}{l}-2.265^{* * *} \\
(-14.03)\end{array}$ & $\begin{array}{l}-0.515^{* *} \\
(-2.15)\end{array}$ & $\begin{array}{l}-2.332^{* * *} \\
(-12.82)\end{array}$ & $\begin{array}{l}-0.122^{* * *} \\
(-11.78)\end{array}$ & $\begin{array}{l}-3.565^{* * *} \\
(-12.13)\end{array}$ & $\begin{array}{l}0.586^{* * *} \\
(3.03)\end{array}$ & $\begin{array}{l}-4.665^{* * *} \\
(-12.83)\end{array}$ \\
\hline PC_Pair & $\begin{array}{l}0.137^{* * *} \\
(25.97)\end{array}$ & $\begin{array}{l}2.587^{* * *} \\
(22.53)\end{array}$ & $\begin{array}{l}0.419 \\
(1.10)\end{array}$ & $\begin{array}{l}2.717^{* * *} \\
(23.34)\end{array}$ & $\begin{array}{l}0.125^{* * *} \\
(19.65)\end{array}$ & $\begin{array}{l}3.635^{* * *} \\
(19.90)\end{array}$ & $\begin{array}{l}0.008 \\
(0.02)\end{array}$ & $\begin{array}{l}3.987^{* * *} \\
(20.85)\end{array}$ \\
\hline PSIFI_Pair & $\begin{array}{l}0.551^{* * *} \\
(15.69)\end{array}$ & $\begin{array}{l}1.903^{* * *} \\
(7.74)\end{array}$ & & & $\begin{array}{l}0.618^{* * *} \\
(29.88)\end{array}$ & $\begin{array}{l}2.133^{* * *} \\
(4.85)\end{array}$ & & \\
\hline NonPSIFI_Pair & $\begin{array}{l}-0.128^{* * *} \\
(-9.27)\end{array}$ & $\begin{array}{l}-1.674^{* * *} \\
(-7.80)\end{array}$ & & & $\begin{array}{l}-0.198^{* * *} \\
(-22.16)\end{array}$ & $\begin{array}{l}-4.500^{* * *} \\
(-18.51)\end{array}$ & & \\
\hline Prod_Size & $\begin{array}{l}0.082^{* * *} \\
(41.08)\end{array}$ & $\begin{array}{l}1.918^{* * *} \\
(59.52)\end{array}$ & $\begin{array}{l}1.200^{* * *} \\
(12.00)\end{array}$ & $\begin{array}{l}1.945^{* * *} \\
(58.45)\end{array}$ & $\begin{array}{l}0.132^{* * *} \\
(55.14)\end{array}$ & $\begin{array}{l}4.222^{* * *} \\
(69.16)\end{array}$ & $\begin{array}{l}1.387^{* * *} \\
(9.80)\end{array}$ & $\begin{array}{l}4.357^{* * *} \\
(65.44)\end{array}$ \\
\hline Prod_Conc_AC & $\begin{array}{l}-3.303^{* * *} \\
(-28.88)\end{array}$ & $\begin{array}{l}-65.265^{* * *} \\
(-26.63)\end{array}$ & $\begin{array}{l}-13.910 \\
(-0.46)\end{array}$ & $\begin{array}{l}-64.997^{* * *} \\
(-26.06)\end{array}$ & & & & \\
\hline Prod_Conc_I & & & & & $\begin{array}{l}-1.815^{* * *} \\
(-4.50)\end{array}$ & $\begin{array}{l}-43.989^{* * *} \\
(-3.77)\end{array}$ & $\begin{array}{l}-7,669.241^{* * *} \\
(-7.22)\end{array}$ & $\begin{array}{l}-42.068^{* * *} \\
(-3.57)\end{array}$ \\
\hline Year-Quarter FE & YES & YES & YES & YES & YES & YES & YES & YES \\
\hline$N$ & $18,247,630$ & $18,247,630$ & 23,440 & $16,945,757$ & $18,940,884$ & $18,940,884$ & 23,564 & $17,591,218$ \\
\hline Pseudo $R^{2}$ & 0.067 & 0.024 & 0.018 & 0.020 & 0.115 & 0.046 & 0.025 & 0.037 \\
\hline
\end{tabular}




\section{Table 5: Common Sales and Return Covariance}

The table presents tobit estimation results for the sample of insurer pairs from 2002 to 2014 . The dependent variable is the natural logarithm of one plus Common Sales_AC or Common Sales_I, defined as the dot product of a pairs asset class or issuer net sales. Ret_Cov_Pair is the annual return covariance of daily holding-period returns for the pair. Similarity_AC or Similarity_I is the cosine similarity between a pair's asset class or issuer portfolio weights. The remaining independent variables are defined in Appendix B. All independent variables are measured as of the year-end prior to the sales quarter. Robust $t$-statistics are in parentheses. Statistical significance is denoted by $* * *$, $* *$, and ${ }^{*}$ at the $1 \%, 5 \%$, and $10 \%$ level respectively.

\begin{tabular}{|c|c|c|c|c|c|c|c|c|}
\hline & \multicolumn{4}{|c|}{ Common Sales - Asset Class } & \multicolumn{4}{|c|}{ Common Sales - Issuer } \\
\hline & $\begin{array}{l}\text { All } \\
\text { Pairs } \\
(1)\end{array}$ & $\begin{array}{l}\text { All } \\
\text { Pairs } \\
(2)\end{array}$ & $\begin{array}{l}\text { PSIFI } \\
\text { Pairs } \\
(3)\end{array}$ & $\begin{array}{c}\text { Non-PSIFI } \\
\text { Pairs } \\
(4)\end{array}$ & $\begin{array}{l}\text { All } \\
\text { Pairs } \\
(5)\end{array}$ & $\begin{array}{c}\text { All } \\
\text { Pairs } \\
(6)\end{array}$ & $\begin{array}{c}\text { PSIFI } \\
\text { Pairs } \\
(7)\end{array}$ & $\begin{array}{l}\text { Non-PSIFI } \\
\text { Pairs } \\
(8)\end{array}$ \\
\hline Ret_Cov_Pair & $\begin{array}{l}118.667 \\
(0.46)\end{array}$ & $\begin{array}{c}-3.106 \\
(-0.01)\end{array}$ & $\begin{array}{l}-604.330^{* *} \\
(-2.10)\end{array}$ & $\begin{array}{l}991.124 \\
(1.33)\end{array}$ & $\begin{array}{l}-402.182 \\
(-1.31)\end{array}$ & $\begin{array}{l}-128.375 \\
(-0.45)\end{array}$ & $\begin{array}{l}-480.803^{* *} \\
(-1.97)\end{array}$ & $\begin{array}{l}-1,570.928^{* *} \\
(-2.10)\end{array}$ \\
\hline Similarity_AC & & $\begin{array}{l}4.615^{* * *} \\
(6.61)\end{array}$ & $\begin{array}{l}5.703^{* * *} \\
(4.56)\end{array}$ & $\begin{array}{l}6.553^{* * *} \\
(7.42)\end{array}$ & & & & \\
\hline Similarity_I & & & & & & $\begin{array}{l}43.359^{* * *} \\
(31.05)\end{array}$ & $\begin{array}{l}22.425^{* * *} \\
(12.38)\end{array}$ & $\begin{array}{l}55.104 * * * \\
(29.29)\end{array}$ \\
\hline Life_Pair & $\begin{array}{l}-0.060 \\
(-0.18)\end{array}$ & $\begin{array}{l}-0.718^{* *} \\
(-2.06)\end{array}$ & $\begin{array}{l}2.487^{* *} \\
(2.08)\end{array}$ & $\begin{array}{l}-1.278^{* * *} \\
(-2.63)\end{array}$ & $\begin{array}{l}1.694^{* * *} \\
(3.97)\end{array}$ & $\begin{array}{l}0.069 \\
(0.17)\end{array}$ & $\begin{array}{l}2.271^{* *} \\
(1.98)\end{array}$ & $\begin{array}{l}-0.550 \\
(-0.88)\end{array}$ \\
\hline PC_Pair & $\begin{array}{l}2.080^{* * *} \\
(3.08)\end{array}$ & $\begin{array}{l}1.822^{* * *} \\
(2.70)\end{array}$ & & $\begin{array}{l}2.321^{* * *} \\
(3.00)\end{array}$ & $\begin{array}{l}-1.914^{* *} \\
(-2.25)\end{array}$ & $\begin{array}{l}-0.256 \\
(-0.33)\end{array}$ & & $\begin{array}{l}-0.368 \\
(-0.38)\end{array}$ \\
\hline PSIFI_Pair & $\begin{array}{l}1.113^{* * *} \\
(2.93)\end{array}$ & $\begin{array}{l}0.799^{* *} \\
(2.14)\end{array}$ & & & $\begin{array}{l}-0.091 \\
(-0.19)\end{array}$ & $\begin{array}{l}-0.942^{* *} \\
(-2.01)\end{array}$ & & \\
\hline NonPSIFI_Pair & $\begin{array}{l}-1.614^{* * *} \\
(-3.51)\end{array}$ & $\begin{array}{l}-1.706^{* * *} \\
(-3.64)\end{array}$ & & & $\begin{array}{l}-1.423^{* * *} \\
(-3.35)\end{array}$ & $\begin{array}{l}-2.015^{* * *} \\
(-4.95)\end{array}$ & & \\
\hline Prod_Size & $\begin{array}{l}2.037^{* * *} \\
(20.89)\end{array}$ & $\begin{array}{l}2.062^{* * *} \\
(21.10)\end{array}$ & $\begin{array}{l}2.133^{* * *} \\
(10.19)\end{array}$ & $\begin{array}{l}2.181^{\text {*** }} \\
(18.20)\end{array}$ & $\begin{array}{l}4.090^{* * *} \\
(34.88)\end{array}$ & $\begin{array}{l}4.127^{* * *} \\
(34.34)\end{array}$ & $\begin{array}{l}3.200^{* * *} \\
(14.11)\end{array}$ & $\begin{array}{l}4.826^{* * *} \\
(27.80)\end{array}$ \\
\hline Prod_Conc_AC & $\begin{array}{l}-76.150^{* * *} \\
(-5.17)\end{array}$ & $\begin{array}{l}-66.497^{* * *} \\
(-4.70)\end{array}$ & $\begin{array}{l}-43.032^{* *} \\
(-2.36)\end{array}$ & $\begin{array}{l}-63.014^{* *} \\
(-2.09)\end{array}$ & & & & \\
\hline Prod_Conc_I & & & & & $\begin{array}{l}-2,108.262^{* * *} \\
(-3.57)\end{array}$ & $\begin{array}{l}-1,938.606 * * * \\
(-3.73)\end{array}$ & $\begin{array}{l}-8,527.551^{* * *} \\
(-6.59)\end{array}$ & $\begin{array}{l}-994.302^{* *} \\
(-2.01)\end{array}$ \\
\hline Year-Quarter FE & YES & YES & YES & YES & YES & YES & YES & YES \\
\hline$N$ & 65,473 & 65,473 & 7,058 & 28,889 & 69,216 & 69,216 & 7,320 & 30,780 \\
\hline Pseudo $R^{2}$ & 0.028 & 0.028 & 0.026 & 0.019 & 0.048 & 0.057 & 0.048 & 0.041 \\
\hline
\end{tabular}


Table 6: Common Sales and Asset Liquidity/Downgrades

The table presents tobit estimation results for the sample of insurer pairs from 2002 to 2014 . The dependent variable is the natural logarithm of one plus Common Sales_AC or Common Sales_I, defined as the dot product of a pair's asset class or issuer net sales. Similarity_AC_Liquid is a pair's asset-class portfolio similarity constructed using only liquid asset classes: equity, mutual fund shares, U.S. government securities, GSE securities, and sovereign bonds. Similarity_AC_Illiquid is a pair's asset-class portfolio similarity constructed using only illiquid asset classes: corporate bonds, municipal bonds, RMBS, CMBS, and ABS. Similarity_I_Downgraded is a pair's portfolio similarity constructed using only issuers downgraded from investment to non-investment grade in the following year. Similarity_I_NotDowngraded is a pair's portfolio similarity constructed using only issuers not downgraded from investment to non-investment grade in the following year. The remaining independent variables are defined in Appendix B. All independent variables are measured as of the year-end prior to the sales quarter. Robust $t$-statistics are in parentheses. Statistical significance is denoted by $* * *, * *$, and $*$ at the $1 \%, 5 \%$, and $10 \%$ level respectively.

\begin{tabular}{|c|c|c|c|c|c|c|}
\hline & \multicolumn{3}{|c|}{ Common Sales - Asset Class } & \multicolumn{3}{|c|}{ Common Sales - Issuer } \\
\hline & $\begin{array}{l}\text { All } \\
\text { Pairs } \\
(1)\end{array}$ & $\begin{array}{l}\text { PSIFI } \\
\text { Pairs } \\
(2) \\
\end{array}$ & $\begin{array}{l}\text { Non-PSIFI } \\
\text { Pairs } \\
(3)\end{array}$ & $\begin{array}{c}\text { All } \\
\text { Pairs } \\
(4)\end{array}$ & $\begin{array}{l}\text { PSIFI } \\
\text { Pairs } \\
(5) \\
\end{array}$ & $\begin{array}{c}\text { Non-PSIFI } \\
\text { Pairs } \\
(6)\end{array}$ \\
\hline Similarity_AC_Illiquid & $\begin{array}{l}3.216^{* * *} \\
(16.38)\end{array}$ & $\begin{array}{l}1.799 * * * \\
(3.46)\end{array}$ & $\begin{array}{l}3.402^{* * *} \\
(16.63)\end{array}$ & & & \\
\hline Similarity_AC_Liquid & $\begin{array}{l}2.321^{* * * *} \\
(12.72)\end{array}$ & $\begin{array}{l}4.275^{* * *} \\
(6.92)\end{array}$ & $\begin{array}{l}2.405^{* * *} \\
(12.38)\end{array}$ & & & \\
\hline Similarity_I_Downgraded & & & & $\begin{array}{l}24.539^{* * *} \\
(31.72)\end{array}$ & $\begin{array}{l}8.907^{* * *} \\
(10.25)\end{array}$ & $\begin{array}{l}25.615^{* * *} \\
(30.52)\end{array}$ \\
\hline Similarity_I_NotDowngraded & & & & $\begin{array}{l}30.600 \text { *** } \\
(36.28)\end{array}$ & $\begin{array}{l}12.995^{* * *} \\
(15.42)\end{array}$ & $\begin{array}{l}31.388^{* * *} \\
(35.38)\end{array}$ \\
\hline Life_Pair & $\begin{array}{l}-2.335^{* * *} \\
(-14.69)\end{array}$ & $\begin{array}{l}-0.230 \\
(-1.07)\end{array}$ & $\begin{array}{l}-2.408^{* * *} \\
(-13.47)\end{array}$ & $\begin{array}{l}-3.920^{* * *} \\
(-13.66)\end{array}$ & $\begin{array}{l}0.447^{* *} \\
(2.26)\end{array}$ & $\begin{array}{l}-4.892^{* * *} \\
(-13.77)\end{array}$ \\
\hline PC_Pair & $\begin{array}{l}2.617^{* * * *} \\
(21.78)\end{array}$ & $\begin{array}{l}0.459 \\
(1.18)\end{array}$ & $\begin{array}{l}2.744^{* * *} \\
(22.40)\end{array}$ & $\begin{array}{l}3.587^{* * *} \\
(18.47)\end{array}$ & $\begin{array}{l}0.428 \\
(0.80)\end{array}$ & $\begin{array}{l}3.956^{* * *} \\
(19.42)\end{array}$ \\
\hline PSIFI_Pair & $\begin{array}{l}1.911^{* * * *} \\
(7.99)\end{array}$ & & & $\begin{array}{l}-2.346^{* * *} \\
(-5.32)\end{array}$ & & \\
\hline NonPSIFI_Pair & $\begin{array}{l}-1.622^{* * *} \\
(-7.61)\end{array}$ & & & $\begin{array}{l}-4.536^{* * *} \\
(-18.15)\end{array}$ & & \\
\hline Prod_Size & $\begin{array}{l}1.907^{* * * *} \\
(59.88)\end{array}$ & $\begin{array}{l}1.264^{* * *} \\
(12.43)\end{array}$ & $\begin{array}{l}1.934^{* * *} \\
(58.90)\end{array}$ & $\begin{array}{l}3.942^{* * *} \\
(71.68)\end{array}$ & $\begin{array}{l}1.019^{* * *} \\
(6.84)\end{array}$ & $\begin{array}{l}4.091^{* * *} \\
(67.43)\end{array}$ \\
\hline Prod_Conc_AC & $\begin{array}{l}-63.853^{* * *} \\
(-26.34)\end{array}$ & $\begin{array}{l}-17.698 \\
(-0.58)\end{array}$ & $\begin{array}{l}-63.463^{* * *} \\
(-25.79)\end{array}$ & & & \\
\hline Prod_Conc_I & & & & $\begin{array}{l}-22.648^{* *} \\
(-2.16)\end{array}$ & $\begin{array}{l}-6,085.102^{* * *} \\
(-6.46)\end{array}$ & $\begin{array}{l}-20.412^{*} \\
(-1.92)\end{array}$ \\
\hline Year-Quarter FE & $18,068,519$ & 23,440 & $16,766,652$ & $18,940,884$ & 23,564 & $17,591,218$ \\
\hline$N$ & YES & YES & YES & YES & YES & YES \\
\hline $\operatorname{Adj} R^{2}$ & 0.024 & 0.019 & 0.021 & 0.049 & 0.029 & 0.040 \\
\hline
\end{tabular}


Table 7: Common Sales and Regulatory Capital Constraints

The table presents OLS estimation results for the sample of insurer pairs from 2002 to 2014. The dependent variable is the natural logarithm of one plus Common Sales_AC or Common Sales_I, defined as the dot product of a pair's asset class or issuer net sales. The sample is restricted to insurer pairs that sell at least on asset class or issuer in common. Similarity_AC or Similarity_I is the cosine similarity between a pair's asset class or issuer portfolio weights. Prod_RBC is the natural logarithm of the product of a pair's RBC ratios (total adjusted capital to authorized control level risk-based capital). RBC_Low_Pair is an indicator variable equal to 1 if the RBC ratio of both insurers in a pair is at or below the bottom quartile of RBC ratios in a given year, 0 otherwise. The remaining independent variables are defined in Appendix B. All independent variables are measured as of the year-end prior to the sales quarter. Robust $t$-statistics are in parentheses. Statistical significance is denoted by $* * *, * *$, and $*$ at the $1 \%, 5 \%$, and $10 \%$ level respectively.

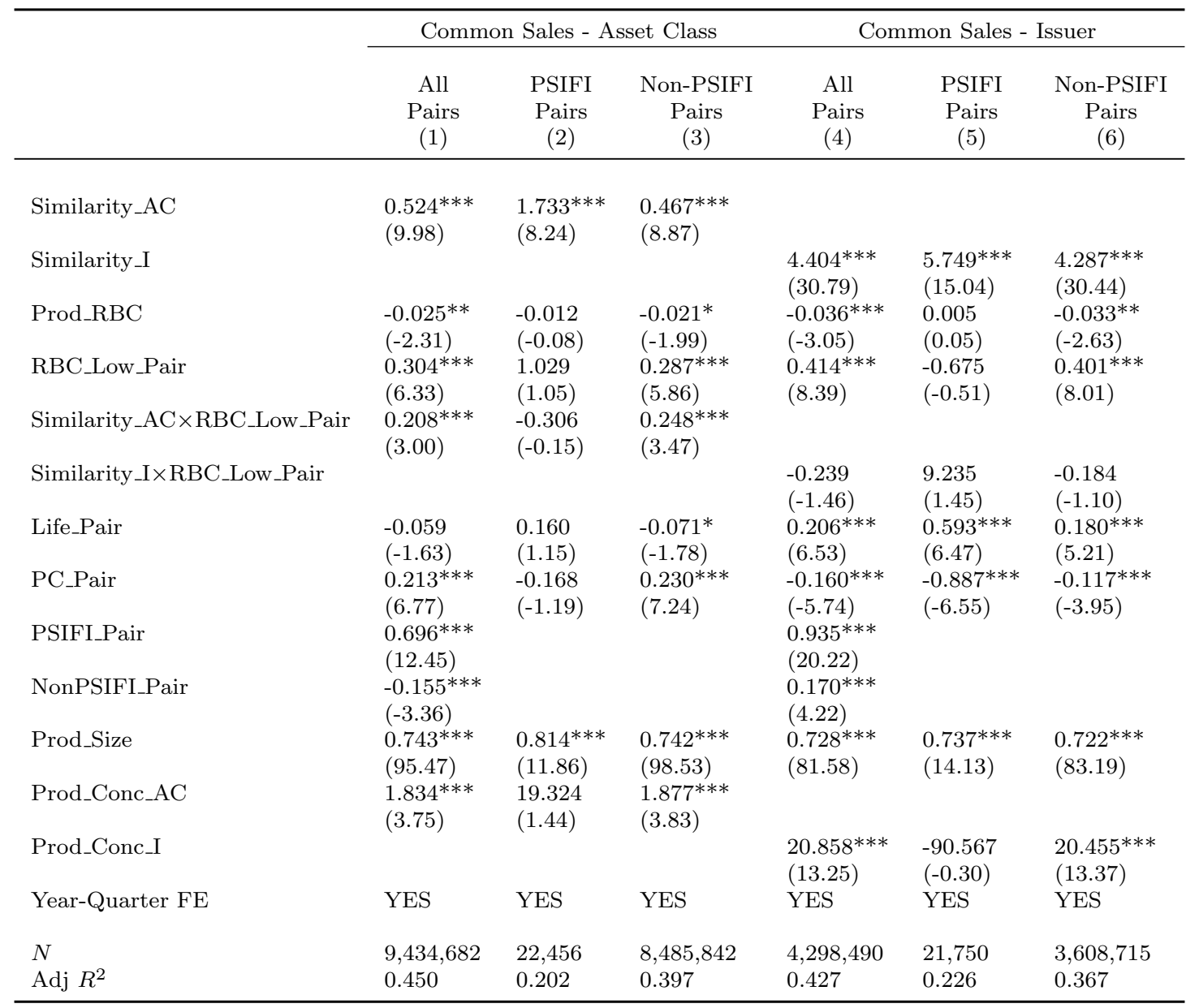


Table 8: Portfolio Similarity and Common Sales During the Crisis

The table presents OLS estimation results for the sample of insurer pairs from 2002 to 2014. The dependent variable is the natural logarithm of one plus Common Sales_AC or Common Sales_I, defined as the dot product of a pair's asset class or issuer net sales. Similarity_AC or Similarity_I is the cosine similarity between a pair's asset class or issuer portfolio weights. The sample is restricted to insurer pairs that sell at least on asset class or issuer in common. Crisis is an indicator variable equal to 1 for the years 2007-2009, 0 otherwise. PostCrisis is an indicator variable equal to 1 for the years 2010-2014, 0 otherwise. The remaining independent variables are defined in Appendix B. All independent variables are measured as of the year-end prior to the sales quarter. Robust $t$-statistics are in parentheses. Statistical significance is denoted by ***,**, and $*$ at the $1 \%, 5 \%$, and $10 \%$ level respectively.

\begin{tabular}{|c|c|c|c|c|c|c|}
\hline & \multicolumn{3}{|c|}{ Common Sales - Asset Class } & \multicolumn{3}{|c|}{ Common Sales - Issuer } \\
\hline & $\begin{array}{c}\text { All } \\
\text { Pairs } \\
(1)\end{array}$ & $\begin{array}{c}\text { PSIFI } \\
\text { Pairs } \\
(2)\end{array}$ & $\begin{array}{c}\text { Non-PSIFI } \\
\text { Pairs } \\
(3)\end{array}$ & $\begin{array}{c}\text { All } \\
\text { Pairs } \\
(4)\end{array}$ & $\begin{array}{c}\text { PSIFI } \\
\text { Pairs } \\
(5)\end{array}$ & $\begin{array}{c}\text { Non-PSIFI } \\
\text { Pairs } \\
(6)\end{array}$ \\
\hline Similarity_AC & $\begin{array}{l}0.485^{* * *} \\
(6.11)\end{array}$ & $\begin{array}{l}0.941^{* * *} \\
(3.63)\end{array}$ & $\begin{array}{l}0.454^{* * *} \\
(5.62)\end{array}$ & & & \\
\hline Similarity_I & & & & $\begin{array}{l}4.898^{* * *} \\
(26.67)\end{array}$ & $\begin{array}{l}6.998^{* * *} \\
(13.97)\end{array}$ & $\begin{array}{l}4.830^{* * *} \\
(25.19)\end{array}$ \\
\hline Crisis & $\begin{array}{l}1.073^{* * *} \\
(14.72)\end{array}$ & $\begin{array}{l}1.395^{* * *} \\
(4.65)\end{array}$ & $\begin{array}{l}1.024^{* * *} \\
(13.57)\end{array}$ & $\begin{array}{l}-0.088^{*} \\
(-1.72)\end{array}$ & $\begin{array}{l}-0.905^{* * *} \\
(-5.12)\end{array}$ & $\begin{array}{c}-0.004 \\
(-0.07)\end{array}$ \\
\hline Similarity_AC $\times$ Crisis & $\begin{array}{l}0.105 \\
(0.76)\end{array}$ & $\begin{array}{l}1.614^{* * *} \\
(3.62)\end{array}$ & $\begin{array}{l}0.066 \\
(0.47)\end{array}$ & & & \\
\hline Similarity_I $\times$ Crisis & & & & $\begin{array}{l}0.130 \\
(0.35)\end{array}$ & $\begin{array}{l}0.295 \\
(0.31)\end{array}$ & $\begin{array}{l}0.015 \\
(0.04)\end{array}$ \\
\hline PostCrisis & $\begin{array}{l}0.692^{* * *} \\
(14.04)\end{array}$ & $\begin{array}{l}0.673^{* *} \\
(2.58)\end{array}$ & $\begin{array}{l}0.665^{* * *} \\
(13.45)\end{array}$ & $\begin{array}{l}-0.666^{* * *} \\
(-18.52)\end{array}$ & $\begin{array}{l}-0.462^{* * *} \\
(-3.08)\end{array}$ & $\begin{array}{l}-0.634^{* * *} \\
(-16.77)\end{array}$ \\
\hline Similarity_AC $\times$ PostCrisis & $\begin{array}{l}0.114 \\
(1.19)\end{array}$ & $\begin{array}{l}0.894^{* *} \\
(2.33)\end{array}$ & $\begin{array}{l}0.097 \\
(1.03)\end{array}$ & & & \\
\hline Similarity_I $\times$ PostCrisis & & & & $\begin{array}{l}-0.969^{* * *} \\
(-4.72)\end{array}$ & $\begin{array}{l}-2.384^{* * *} \\
(-3.55)\end{array}$ & $\begin{array}{l}-1.010^{* * *} \\
(-4.81)\end{array}$ \\
\hline Life_Pair & $\begin{array}{l}-0.070^{*} \\
(-1.99)\end{array}$ & $\begin{array}{l}0.149 \\
(1.05)\end{array}$ & $\begin{array}{l}-0.085^{* *} \\
(-2.18)\end{array}$ & $\begin{array}{l}0.184^{* * *} \\
(5.87)\end{array}$ & $\begin{array}{l}0.607^{* * *} \\
(6.75)\end{array}$ & $\begin{array}{l}0.154^{* * *} \\
(4.52)\end{array}$ \\
\hline PC_Pair & $\begin{array}{l}0.222^{* * *} \\
(7.44)\end{array}$ & $\begin{array}{l}-0.162 \\
(-1.14)\end{array}$ & $\begin{array}{l}0.237^{* * *} \\
(7.88)\end{array}$ & $\begin{array}{l}-0.132^{* * *} \\
(-5.06)\end{array}$ & $\begin{array}{l}-0.929^{* * *} \\
(-7.20)\end{array}$ & $\begin{array}{l}-0.086^{* * *} \\
(-3.10)\end{array}$ \\
\hline PSIFI_Pair & $\begin{array}{l}0.672^{* * *} \\
(11.71)\end{array}$ & & & $\begin{array}{l}0.911^{* * *} \\
(19.42)\end{array}$ & & \\
\hline NonPSIFI_Pair & $\begin{array}{l}-0.114^{* *} \\
(-2.41)\end{array}$ & & & $\begin{array}{l}0.209^{* * *} \\
(5.17)\end{array}$ & & \\
\hline Prod_Size & $\begin{array}{l}0.749^{* * *} \\
(100.73)\end{array}$ & $\begin{array}{l}0.819^{* * *} \\
(12.23)\end{array}$ & $\begin{array}{l}0.747^{* * *} \\
(103.83)\end{array}$ & $\begin{array}{l}0.734^{* * *} \\
(82.74)\end{array}$ & $\begin{array}{l}0.725^{* * *} \\
(13.92)\end{array}$ & $\begin{array}{l}0.728^{* * *} \\
(84.69)\end{array}$ \\
\hline Prod_Conc_AC & $\begin{array}{l}2.316^{* * *} \\
(4.80)\end{array}$ & $\begin{array}{l}18.877 \\
(1.42)\end{array}$ & $\begin{array}{l}2.346^{* * *} \\
(4.85)\end{array}$ & & & \\
\hline Prod_Conc_I & & & & $\begin{array}{l}20.476^{* * *} \\
(15.39)\end{array}$ & $\begin{array}{l}-12.946 \\
(-0.05)\end{array}$ & $\begin{array}{l}20.103^{* * *} \\
(15.52)\end{array}$ \\
\hline Year-Quarter FE & YES & YES & YES & YES & YES & YES \\
\hline$N$ & $10,071,447$ & 22,456 & $9,088,672$ & $4,526,813$ & 21,750 & $3,817,021$ \\
\hline $\operatorname{Adj} R^{2}$ & 0.458 & 0.204 & 0.408 & 0.433 & 0.230 & 0.376 \\
\hline
\end{tabular}




\section{Table 9: Liquidity Shock and Common Sales}

The table presents tobit estimation for the sample of P\&C insurer pairs from 2002 to 2014. The dependent variable is the natural logarithm of one plus Common Sales_I, defined as the dot product of a pair's issuer net sales. Similarity_I is the cosine similarity between a pair's issuer portfolio weights. Exposed is an indicator variable equal to 1 if both insurers' premiums written in affected states (Mississippi and Louisiana) relative to all premiums written, are in the top quartile of the sample for the year, and 0 otherwise. Hurricane is an indicator variable equal to 1 in the third quarter of 2005, and 0 otherwise. The remaining independent variables are defined in Appendix B. Mixed pairs are those comprised of an exposed and non-exposed insurers. All independent variables are measured as of the year-end prior to the sales quarter. Robust $t$-statistics are in parentheses. Statistical significance is denoted by ***, **, and * at the $1 \%, 5 \%$, and $10 \%$ level respectively.

\begin{tabular}{|c|c|c|c|}
\hline & $\begin{array}{c}\text { All P\&C Pairs } \\
\text { (1) }\end{array}$ & $\begin{array}{l}\text { Excluding Mixed Pairs } \\
(2)\end{array}$ & $\begin{array}{l}\text { Only Exposed Pairs } \\
\text { (3) }\end{array}$ \\
\hline Similarity_I & $\begin{array}{l}28.252^{* * *} \\
(36.04)\end{array}$ & $\begin{array}{c}27.327^{* * *} \\
(36.28)\end{array}$ & $\begin{array}{c}30.044^{* * *} \\
(22.15)\end{array}$ \\
\hline Similarity_I*Hurricane*Exposed & $\begin{array}{c}6.416^{* * *} \\
(5.80)\end{array}$ & $\begin{array}{c}8.853^{* * *} \\
(6.18)\end{array}$ & \\
\hline Similarity_I*Hurricane & $\begin{array}{l}0.399 \\
(0.57)\end{array}$ & $\begin{array}{c}-1.795^{* * *} \\
(-2.58)\end{array}$ & $\begin{array}{c}5.254^{* * *} \\
(3.98)\end{array}$ \\
\hline Similarity_I*Exposed & $\begin{array}{l}2.006^{*} \\
(1.88)\end{array}$ & $\begin{array}{c}2.936^{* *} \\
(2.12)\end{array}$ & \\
\hline Hurricane*Exposed & $\begin{array}{c}1.822^{* * *} \\
(4.99)\end{array}$ & $\begin{array}{l}2.350^{* * *} \\
(5.11)\end{array}$ & \\
\hline Hurricane & $\begin{array}{c}-1.011^{* * *} \\
(-7.93)\end{array}$ & $\begin{array}{c}-1.295^{* * *} \\
(-9.23)\end{array}$ & $\begin{array}{l}-0.366 \\
(-1.55)\end{array}$ \\
\hline Exposed & $\begin{array}{c}-2.021^{* * *} \\
(-6.50)\end{array}$ & $\begin{array}{c}-3.150^{* * *} \\
(-7.56)\end{array}$ & \\
\hline Prod_Size & $\begin{array}{c}4.182^{* * *} \\
(63.00)\end{array}$ & $\begin{array}{c}4.259^{* * *} \\
(61.50)\end{array}$ & $\begin{array}{c}4.214^{* * *} \\
(52.85)\end{array}$ \\
\hline Prod_Conc_I & $\begin{array}{c}-40.656^{* * *} \\
(-3.35)\end{array}$ & $\begin{array}{c}-30.213^{* * *} \\
(-2.97)\end{array}$ & $\begin{array}{c}-103.693^{* *} \\
(-2.39)\end{array}$ \\
\hline $\mathrm{N}$ & $9,368,378$ & $5,704,588$ & 657,504 \\
\hline Pseudo $R^{2}$ & 0.036 & 0.036 & 0.042 \\
\hline
\end{tabular}


Table 10: Liquidity Shock and Price Impact

The table presents cross-sectional OLS estimation for the sample of P\&C insurer pairs for which the dependent variable can be calculated. The dependent variable is a pair's joint portfolio yield spread change from $2005 \mathrm{Q} 2$ (prior to Hurricanes Katrina and Rita) to 2005Q4 (after the hurricanes), defined as the weighted average of the insurers in the pair's portfolio yield spread change, using the par value of the bonds held by each insurer at the end of 2004 as the weight. An insurer's portfolio yield spread change is the weighted average yield spread change of the corporate bonds in its portfolio, using each bond's par value held at the end of 2004 as the weight. The yield spread change of a bond is its yield spread at the end of 2005Q4 minus the yield spread at the end of 2005Q2, where a yield spread is the bond's yield to maturity minus that on a maturity-matched Treasury. Exposed is an indicator variable equal to 1 if both insurers' premiums written in affected states (Mississippi and Louisiana) relative to all premiums written, are in the top quartile of the sample for the year, and 0 otherwise. Avg. Ln(Trades) is the weighted average of the number of trades in the two quarters prior to the hurricanes; $A v g . L n(A m t)$ is the weighted average of the natural logarithm of the bonds' issuance amount; and Avg. Ln(Mat) is the weighted average natural logarithm of the bond's years to maturity. Mixed pairs are those comprised of an exposed and non-exposed insurers. $t$-statistics are in parentheses. Statistical significance is denoted by ${ }^{* *}, * *$, and $*$ at the $1 \%, 5 \%$, and $10 \%$ level respectively.

\begin{tabular}{lccc}
\hline & All P\&C Pairs & Excluding Mixed Pairs & Only Exposed Pairs \\
& $(1)$ & $(2)$ & $(3)$ \\
\hline Similarity_I & $-0.070^{* * *}$ & $-0.152^{* * *}$ & $0.138^{* * *}$ \\
& $(0.007)$ & $(0.009)$ & $(0.023)$ \\
Exposed & -0.008 & $-0.026^{* * *}$ & \\
& $(0.005)$ & $(0.005)$ & \\
Similarity_I*Exposed & $0.098^{* * *}$ & $0.155^{* * *}$ & $0.084^{* * *}$ \\
& $(0.024)$ & $(0.024)$ & $(0.010)$ \\
Avg. Ln(Trades) & $0.181^{* * *}$ & $0.200^{* * *}$ & $-0.139^{* * *}$ \\
& $(0.002)$ & $(0.003)$ & $(0.015)$ \\
Avg. Ln(Amount) & $-0.165^{* * *}$ & $-0.159^{* * *}$ & $0.080^{* * *}$ \\
& $(0.002)$ & $(0.003)$ & $(0.011)$ \\
Avg. Ln(Maturity) & $0.032^{* * *}$ & $0.020^{* * *}$ & $-0.028^{* * *}$ \\
& $(0.003)$ & $(0.004)$ & $(0.001)$ \\
Prod_Size & $-0.015^{* * *}$ & $-0.010^{* * *}$ & $-44.287^{* * *}$ \\
& $(0.000)$ & $(0.001)$ & $(1.521)$ \\
Proc_Conc_I & $-6.656^{* * *}$ & $-1.326^{* * *}$ & $0.009^{* *}$ \\
& $(0.255)$ & $(0.305)$ & $(0.004)$ \\
Prod_RBC & 0.001 & -0.000 & $0.062^{* * *}$ \\
& $(0.001)$ & $(0.001)$ & $(0.013)$ \\
RBC_Low_Pair & $0.026^{* * *}$ & $0.018^{* * *}$ & $2.409^{* * *}$ \\
& $(0.004)$ & $(0.005)$ & $(0.162)$ \\
Constant & $1.782^{* * *}$ & $1.445^{* * *}$ & 14,128 \\
& $(0.025)$ & $(0.030)$ & 0.095 \\
$N$ & & & \\
Adj. $R^{2}$ & 187,673 & 112,652 & 0.077 \\
\hline
\end{tabular}


Table 11: Portfolio Similarity as a Determinant of Common Sales at the Insurer Level

The table presents tobit estimation results for the sample of insurers from 2002 to 2014 . The dependent variable is the natural logarithm of one plus either Common_Sales_Aggr_AC or Common_Sales_Aggr_I, defined as the sum of an insurer's pairwise common sales with all other insurers, at the asset class or issuer level. Similarity_Avg_AC or Similarity_ $A v g_{-} I$ is the average of an insurer's portfolio similarities with all other insurers at the asset class or issuer level. Life and $P C$ are indicator variables equal to 1 if the insurer is a life or a $\mathrm{P} \& \mathrm{C}$ insurer respectively, and 0 otherwise. PSIFI is an indicator variable equal to 1 if an insurer has $\$ 50$ billion or more in assets (excluding those in separate accounts) in at least one year during the sample period, and 0 otherwise. Size is the natural logarithm of an insurer's portfolio assets. Conc_AC or Conc_I is the concentration of an insurer's portfolio at the asset class or issuer level. All independent variables are measured as of the year-end prior to the sales quarter. Robust $t$-statistics are in parentheses. Statistical significance is denoted by $* * *, * *$, and ${ }^{*}$ at the $1 \%, 5 \%$, and $10 \%$ level respectively.

\begin{tabular}{|c|c|c|c|c|c|c|}
\hline & \multicolumn{3}{|c|}{ Common Sales - Asset Class } & \multicolumn{3}{|c|}{ Common Sales - Issuer } \\
\hline & $\begin{array}{l}\text { All } \\
\text { Pairs } \\
(1)\end{array}$ & $\begin{array}{l}\text { PSIFI } \\
\text { Pairs } \\
(2)\end{array}$ & $\begin{array}{c}\text { Non-PSIFI } \\
\text { Pairs } \\
(3)\end{array}$ & $\begin{array}{l}\text { All } \\
\text { Pairs } \\
(4)\end{array}$ & $\begin{array}{c}\text { PSIFI } \\
\text { Pairs } \\
(5)\end{array}$ & $\begin{array}{c}\text { Non-PSIFI } \\
\text { Pairs } \\
(6)\end{array}$ \\
\hline Similarity_Avg_AC & $\begin{array}{l}0.388^{* * *} \\
(2.64)\end{array}$ & $\begin{array}{l}3.329 * * * \\
(9.05)\end{array}$ & $\begin{array}{l}0.312^{* *} \\
(2.06)\end{array}$ & & & \\
\hline Similarity_Avg_I & & & & $\begin{array}{l}13.039^{* * *} \\
(34.98)\end{array}$ & $\begin{array}{l}12.610^{* * *} \\
(15.49)\end{array}$ & $\begin{array}{l}13.092^{* * *} \\
(34.39)\end{array}$ \\
\hline Life & $\begin{array}{l}-0.123^{* *} \\
(-2.00)\end{array}$ & $\begin{array}{l}0.292^{*} \\
(1.66)\end{array}$ & $\begin{array}{l}-0.144^{* *} \\
(-2.27)\end{array}$ & $\begin{array}{l}-0.360^{* * *} \\
(-4.66)\end{array}$ & $\begin{array}{l}0.112 \\
(0.51)\end{array}$ & $\begin{array}{l}-0.390^{* * *} \\
(-4.84)\end{array}$ \\
\hline $\mathrm{PC}$ & $\begin{array}{l}0.151^{* * *} \\
(3.03)\end{array}$ & $\begin{array}{l}-0.361^{* *} \\
(-2.13)\end{array}$ & $\begin{array}{l}0.161^{* * *} \\
(3.13)\end{array}$ & $\begin{array}{l}-0.232^{* * *} \\
(-2.92)\end{array}$ & $\begin{array}{l}-1.022^{* * *} \\
(-4.47)\end{array}$ & $\begin{array}{l}-0.219 * * * \\
(-2.70)\end{array}$ \\
\hline PSIFI & $\begin{array}{l}0.559^{* * *} \\
(11.17)\end{array}$ & & & $\begin{array}{l}-0.287^{* * *} \\
(-3.14)\end{array}$ & & \\
\hline Size & $\begin{array}{l}0.859^{* * *} \\
(116.56)\end{array}$ & $\begin{array}{l}0.682^{* * *} \\
(9.97)\end{array}$ & $\begin{array}{l}0.861^{* * *} \\
(119.65)\end{array}$ & $\begin{array}{l}1.317^{* * *} \\
(78.99)\end{array}$ & $\begin{array}{l}0.795^{* * *} \\
(11.31)\end{array}$ & $\begin{array}{l}1.322^{* * *} \\
(78.80)\end{array}$ \\
\hline Conc_AC & $\begin{array}{l}0.325^{* * *} \\
(3.06)\end{array}$ & $\begin{array}{l}3.366^{* *} \\
(2.57)\end{array}$ & $\begin{array}{l}0.313^{* * *} \\
(2.93)\end{array}$ & & & \\
\hline Conc_I & & & & $\begin{array}{l}-1.653^{* * *} \\
(-3.46)\end{array}$ & $\begin{array}{l}10.594^{* *} \\
(2.16)\end{array}$ & $\begin{array}{l}-1.651 \text { *** } \\
(-3.44)\end{array}$ \\
\hline Year-Quarter FE & YES & YES & YES & YES & YES & YES \\
\hline$N$ & 41,821 & 1,524 & 40,297 & 43,478 & 1,528 & 41,950 \\
\hline Pseudo $R^{2}$ & 0.164 & 0.108 & 0.144 & 0.054 & 0.109 & 0.047 \\
\hline
\end{tabular}




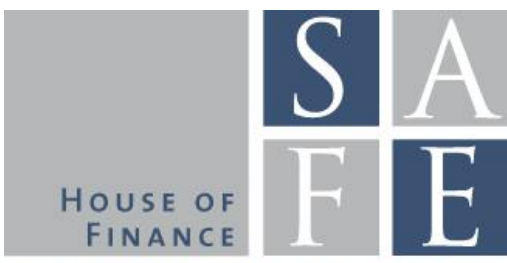

WORKING PAPER SERIES

\section{Recent Issues}

No. 223 Florian Deuflhard

No. 222 Vanessa Endrejat, Matthias Thiemann

No. 221 Axel H. Börsch-Supan, Klaus Härtl, Duarte N. Leite, Alexander Ludwig

No. 220 Yangming Bao, Martin R. Goetz

No. 219 Andreas Hackethal - Christine Laudenbach - Steffen Meyer Annika Weber

No. 218 Florian Hoffmann, Roman Inderst, Marcus Opp

No. 217 Maddalena Davoli, Jia Hou

No. 216 Stefano Colonnello, Giuliano Curatola, Alessandro Gioffré

No. 215 Zsuzsa R. Huszár, Zorka Simon

No. 214 Edin Ibrocevic, Matthias Thiemann

No. 213 Klaus Gugler, Michael Weichselbaumer, Christine Zulehner
Quantifying Inertia in Retail Deposit Markets

Reviving the Shadow Banking Chain in Europe: Regulatory Agency, Technical Complexity and the Dynamics of CoHabitation

Endogenous Retirement Behavior of Heterogeneous Households Under Pension Reforms

Local Peer Effects and Corporate Investment

Client Involvement in Expert Advice Antibiotics in Finance?

Only Time will Tell: A Theory of Deferred Compensation

Financial Literacy and Socialist Education: Lessons from the German Reunification

Pricing Sin Stocks: Ethical Preference vs. Risk Aversion

The Pricing Implications of the Oligopolistic Securities Lending Market: A Beneficial Owner Perspective

All Economic Ideas are Equal, but Some are more Equal than Others: A Differentiated Perspective on Macroprudential Ideas and their Implementation

Effects of Government Spending on Employment: Evidence from Winners and Runners-up in Procurement Auctions 